\title{
Article \\ Development and Evaluation of Energy-Saving Electro-Hydraulic Actuator
}

\author{
Triet Hung Ho ${ }^{1,2}$ (1) and Thanh Danh Le ${ }^{3, *}$ \\ 1 Faculty of Mechanical Engineering, Ho Chi Minh City University of Technology, 268 Ly Thuong Kiet Street, \\ District 10, Ho Chi Minh City 72506, Vietnam; hthung@hcmut.edu.vn \\ 2 Vietnam National University Ho Chi Minh City (VNU-HCM), Linh Trung Ward, Thu Duc District, \\ Ho Chi Minh City 71300, Vietnam \\ 3 Industrial University of Ho Chi Minh City, 12 Nguyen Van Bao Street, Go Vap District, \\ Ho Chi Minh City 71400, Vietnam \\ * Correspondence: lethanhdanh@iuh.edu.vn
}

check for

updates

Citation: Ho, T.H.; Le, T.D. Development and Evaluation of Energy-Saving Electro-Hydraulic Actuator. Actuators 2021, 10, 302. https://doi.org/10.3390/act10110302

Academic Editor: Andrea Vacca

Received: 9 August 2021

Accepted: 11 November 2021

Published: 17 November 2021

Publisher's Note: MDPI stays neutral with regard to jurisdictional claims in published maps and institutional affiliations.

Copyright: (C) 2021 by the authors. Licensee MDPI, Basel, Switzerland. This article is an open access article distributed under the terms and conditions of the Creative Commons Attribution (CC BY) license (https:/ / creativecommons.org/licenses/by/ $4.0 /)$.

\begin{abstract}
This paper will develop a novel electro-hydraulic actuator with energy saving characteristics. This system is able to work in differential configurations through the shifting algorithm of the valves, meaning that this developed system can be adjusted flexibly to obtain the desirable working requirements including the high effectiveness of energy recovery from the load, high velocity or torque. Instead of establishing the mathematical model for the purpose of the dynamic analysis, a model of the developed actuator is built in AMESim software. The simulation results reveal that the system is able to save approximately $20 \%$ energy consumption compared with a traditional without energy recovery EHA. Furthermore, to evaluate the accuracy of the model, experiments will be performed that prove strongly that the experimental results are well matched to the results attained from the simulation model. This work also offers a useful insight into designing and analyzing hydraulic systems without experiments.
\end{abstract}

Keywords: electro-hydraulic actuator (EHA); switching control valves; energy saving hydraulic system

\section{Introduction}

Nowadays, valve controlled hydraulic systems are widely applied in industry such as presses because of good dynamic response. However, the most common drawback of traditional valve-controlled hydraulic systems is low efficiency in many operation points due to throttling control or mismatch power [1-3]. To overcome these problems, many works have been conducted and these studies are briefly reviewed as follows.

Based on the valve controlled systems, some modifications for multi-actuator systems are proposed to reduce energy loss of throttling control [4-8]. The simulation results proved that these systems significantly reduce the energy losses. However, the energy losses were fairly high in such systems.

Load sensing systems (LS) are considered as state of the art of hydraulic systems because of high efficiency and good performance. They have been widely applied in hydraulic mobile applications, especially for multi-actuator systems. However, losses in the LS systems were still remained due to principle of working of load sensing pump and throttling control [9-12].

Digital hydraulic systems are another solution to control flow into the actuator by controlling the on/off high speed valve. Compared with basis valve controlled systems, the digital hydraulic system considerably reduces energy loss. Moreover, studies on the control algorithms as well as optimization of digital hydraulic systems have been conducted, which prove these systems have great application potential in industry or construction machinery [13-16]. However, energy recovery has not been studied for the digital hydraulic systems yet. 
In displacement controlled systems, flow into the actuator is controlled by adjusting the displacement of the hydraulic pump. Therefore, losses deal to the throttling control are totally neglected. Although the displacement controlled systems have high efficiency, the performance of these systems are worse than that of the valve controlled systems $[1,9,17,18]$.

The hydraulic transformer system has been developed based on the pressure coupling type of hydraulic system $[19,20]$. The hydraulic transformer system is able to recover energy as well good tracking control but it requires more equipment to fabricate a hydraulic system when compared with the above systems. The hydraulic transformer is suitable for heavy multi-actuator hydraulic systems.

The electro-hydraulic actuator (EHA) is considered as an energy saving hydraulic system. The EHA systems have been proven to have high recovery efficiency and good performance [21,22]. Modern control algorithms have been designed for such systems to improve applicability of EHA systems into industries [23-26]. However, the cost and the low specific power for the EHA systems using batteries or the low specific energy for the EHA systems using super capacitors are the drawbacks of the EHA systems [27].

In this study, a novel energy saving hydraulic system is proposed and investigated. The system is a pump controlled hydraulic system developed for the cylinder actuator. The proposed system has advanced characteristics in both energy saving and high specific power by using a hydraulic accumulator. The energy saving potential of the system is obtained by recovering energy as well not using throttle valves. The hydraulic accumulator is used to store the recovery energy in the charging phase and to boost the pump in the discharging phase.

The rest of this paper is organized as follows. Section 2 presents the proposed system from the principle of working to control strategy. A model of the system using AMESim software is built in Section 3. Simulation results are presented in Section 4. Experimental setup and results are discussed in Section 5. Finally, some conclusions are given in Section 6.

\section{Proposed Energy Saving Hydraulic System}

\subsection{Hydraulic Circuit}

The proposed system is presented in Figure 1. The system includes an AC servo motor (M), a fix displacement hydraulic pump (P), a hydraulic cylinder, seven directional controlled valves $\left(\mathrm{V}_{1}, \ldots, \mathrm{V}_{7}\right)$, a tank (Tank), a high pressure hydraulic accumulator (HA) and a relief valve RV. In the system, a low pressure accumulator is used as a tank to boost the pump via check valve $\mathrm{CV}_{2}$. Two check valves $\left(\mathrm{CV}_{1}, \mathrm{CV}_{2}\right)$ pilot the flow direction to the pump. In this system, the speed of the hydraulic cylinder is controlled by adjusting the speed of the pump. The high pressure accumulator is used to store recovery energy and serves as a booster of the pump.

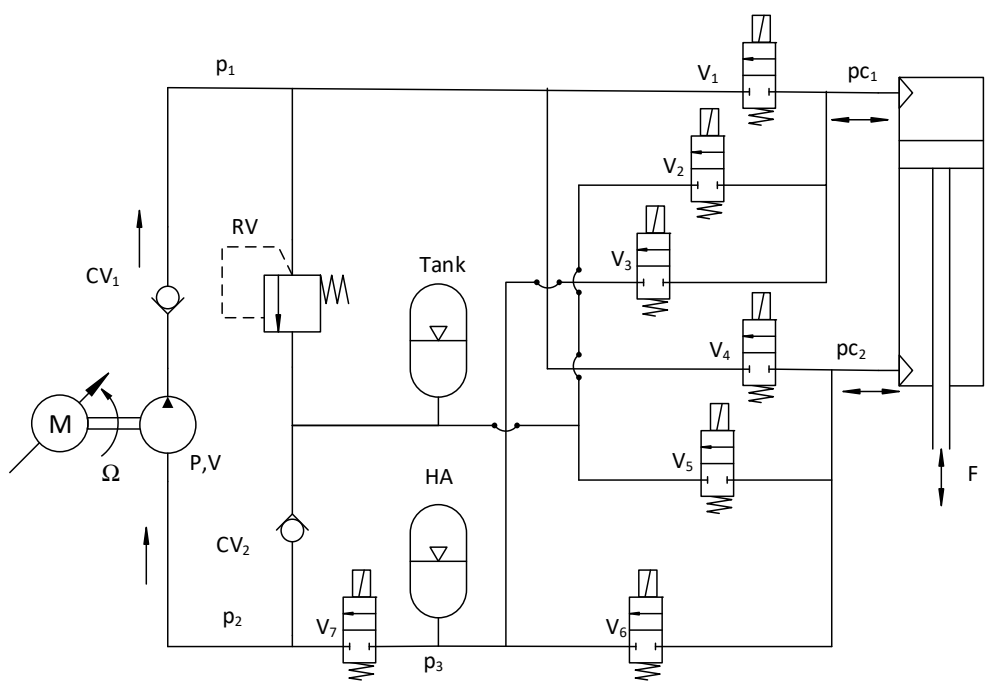

Figure 1. Proposed hydraulic system. 
By switching the seven controlled valves, the system can utilize different working modes that are defined and described in Table 1.

Table 1. Working modes of the hydraulic system.

\begin{tabular}{ccccccccc}
\hline \multirow{2}{*}{ No } & \multirow{2}{*}{ Defining Working Modes } & \multicolumn{7}{c}{ Control Vales } \\
\cline { 3 - 8 } & & $\mathbf{v}_{\mathbf{1}}$ & $\mathbf{v}_{\mathbf{2}}$ & $\mathbf{v}_{\mathbf{3}}$ & $\mathbf{v}_{\mathbf{4}}$ & $\mathbf{v}_{\mathbf{5}}$ & $\mathbf{v}_{\mathbf{6}}$ & $\mathbf{v}_{\mathbf{7}}$ \\
\hline 1 & Normal-out mode (NOM) & ON & OFF & OFF & OFF & ON & OFF & OFF \\
\hline 2 & Normal-in mode (NIM) & OFF & ON & OFF & ON & OFF & OFF & OFF \\
\hline 3 & Regenerative mode (RGOM) & ON & OFF & OFF & ON & OFF & OFF & OFF \\
\hline 4 & Recovery-out mode (RCOM) & ON & OFF & OFF & OFF & OFF & ON & OFF \\
\hline 5 & Recovery-in mode (RCIM) & OFF & OFF & ON & ON & OFF & OFF & OFF \\
\hline 6 & Reused normal-out mode (RUNO) & ON & OFF & OFF & OFF & ON & OFF & ON \\
\hline 7 & Reused normal-in mode (RUNI) & OFF & ON & OFF & ON & OFF & OFF & ON \\
\hline 8 & Reused regenerative mode (RURG) & ON & OFF & OFF & ON & OFF & OFF & ON \\
\hline 9 & Charging accumulator mode (CAM) & ON & OFF & ON & OFF & OFF & OFF & OFF \\
\hline 10 & Unloading pump mode (ULM) & ON & ON & OFF & OFF & OFF & OFF & OFF \\
\hline
\end{tabular}

The working modes of the system are described in following section. Using conditions in Table 1, the hydraulic circuit is redrawn according to each mode as follows. The normalout and normal-in modes are described in Figure 2a,b, respectively. This is an open circuit EHA system and outputs of the cylinder are controlled by adjusting speed of the pump. This is an open circuit because the out port of the cylinder and suction port of the pump are connected directly to the tank. High force is an outstanding characteristic of the normal-out mode.

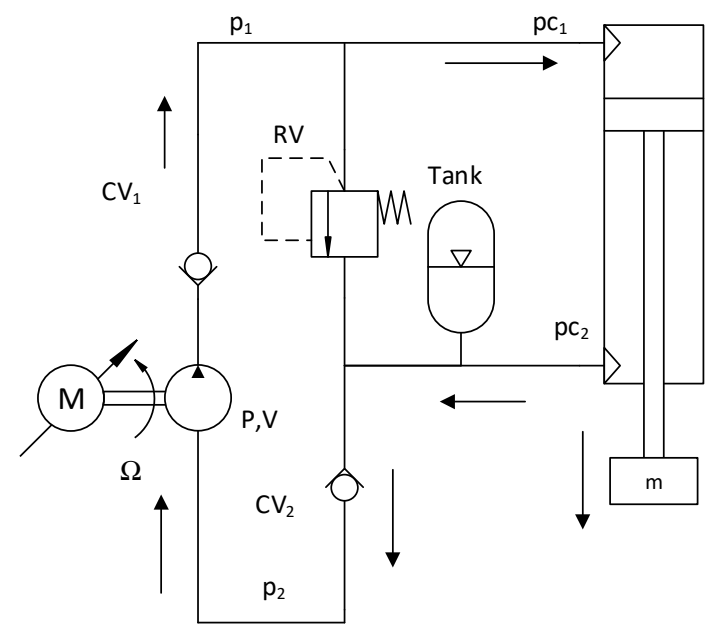

(a)

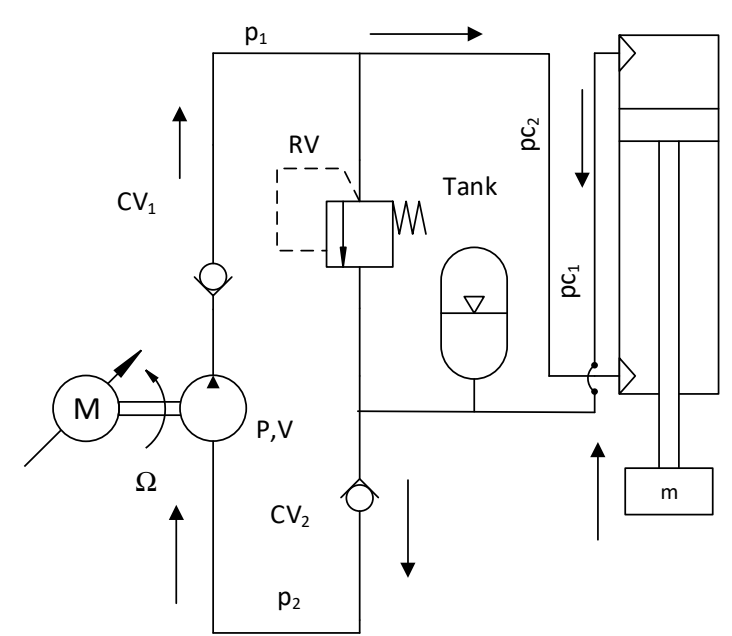

(b)

Figure 2. (a) Normal-out mode. (b) Normal-in mode.

The regenerative mode is described in Figure 3. In this mode, the cylinder is only extended. The speed of the cylinder is faster, while the pressure $p_{1}$ is higher to yield to the same force at the cylinder rod when compared with that of the normal-out mode. 


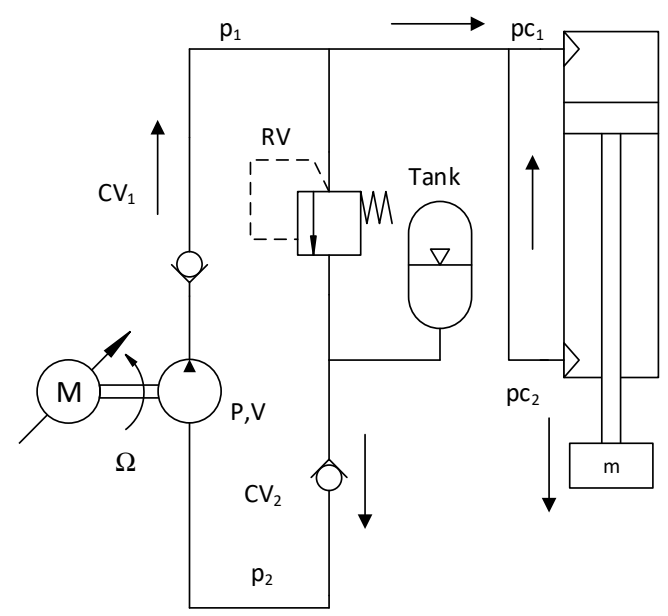

Figure 3. Regenerative-out mode.

The recovery-in and the recovery-out modes are described in Figure 4a,b, respectively. The system is in recovery-in mode when an external force pushes the cylinder to retract. In this mode, the energy of the external force is recovered and stored in the accumulator in form of hydraulic energy. On the other hand, when an external force pulls the cylinder to extend the system it works in recovery-out mode. As a result, the energy of the external forces can be recovered in both directions of the cylinder. The pressure in the accumulator increases during the recovery modes.

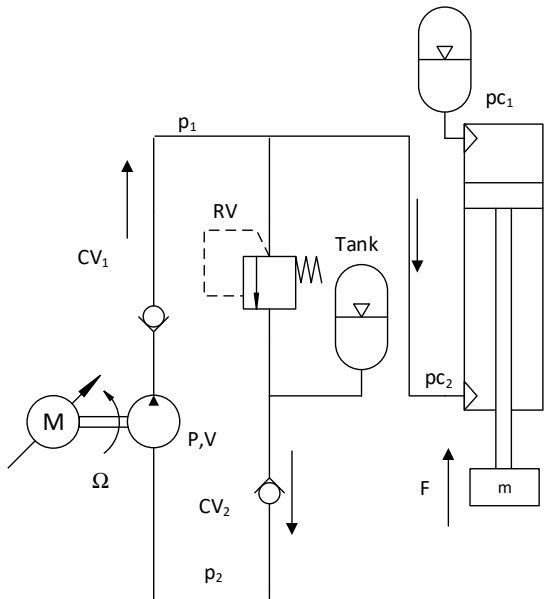

(a)

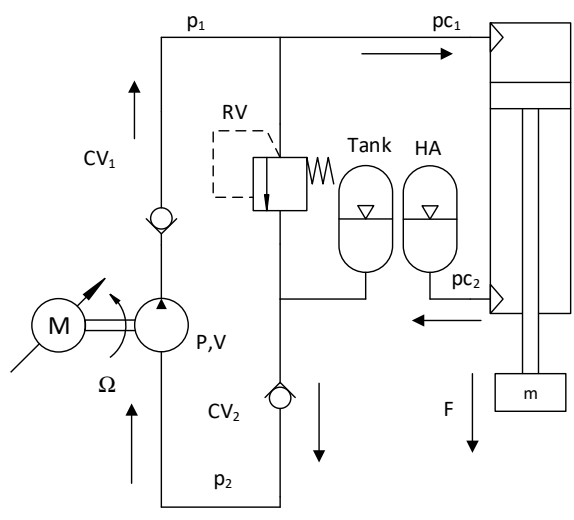

(b)

Figure 4. (a) Recovery-in mode. (b) Recovery-out mode.

Reused normal-out, reused normal-in and reused regenerative-out modes are shown in Figure 5. In these reused modes, the accumulator is directly connected to suction port of the pump. Pressure of fluid in the accumulator varies from $\mathrm{p}_{\text {high }}$ to $\mathrm{p}_{\text {low }}$ in respect to beginning and ending period of these modes. The pressure of fluid in the accumulator reduces different pressure between the two ports of the pump. As a result, torque at the pump shaft is reduced in these reused modes when compared with the previous modes. 


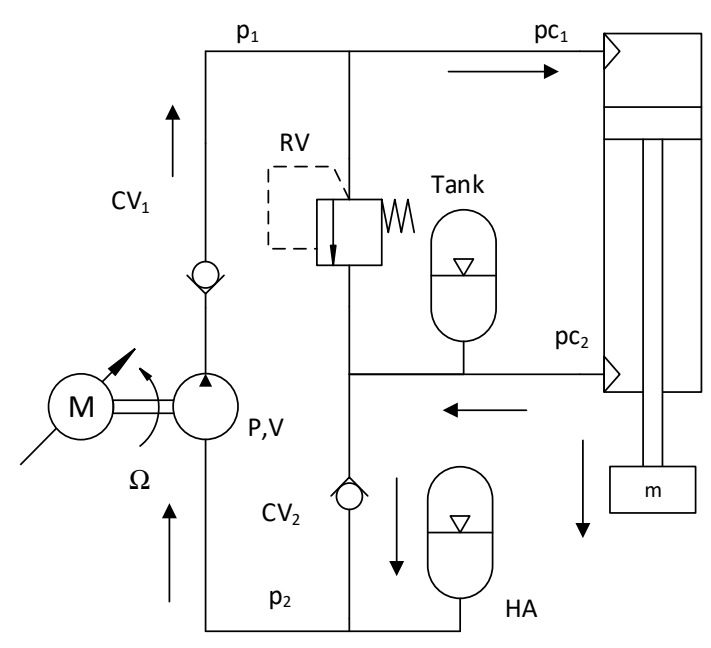

(a)

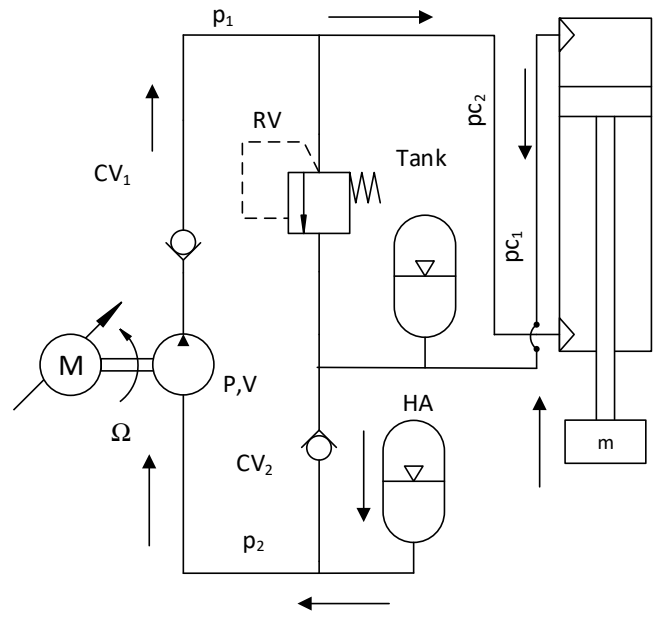

(b)

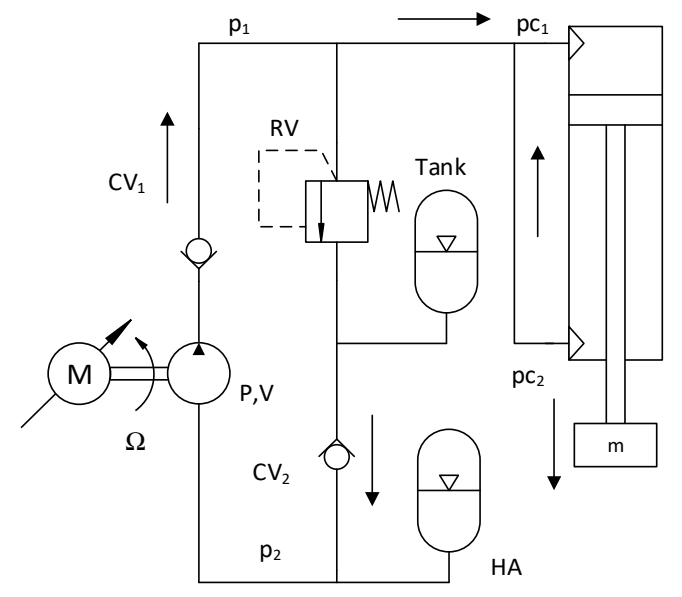

(c)

Figure 5. (a) Reused normal-out mode; (b) reused normal-in mode; (c) reused regenerative-out mode.

The reused regenerative mode (RURG) is shown in Figure $5 \mathrm{c}$. In a regenerative mode, flow in hydraulic circuit is regeneratively connected so that the cylinder has a high velocity but low force when compared with that values for a normal-out mode. However, the accumulator works as a booster of the pump in reused regenerative mode so the working pressure $\mathrm{p}_{1}$ is able to increase. As a result, the system achieves not only high velocity but also high force of the cylinder for reused regenerative mode.

It can be observed that the roles of the accumulator in the system are storing recovery energy in the two recovery modes and boosting the pump in the three reused working modes. This implies that the accumulator partially aids power along with the electric motor to drive the pump.

As mentioned above, the reused regenerative mode has advantages about force and velocity. If recovery energy stored in the accumulator is not enough to use next phase, the accumulator should be charged in advance a given level by the pump. In applications where recovery energy is not available the accumulator can be pre-charged to boost the pump if required power of the cylinder is higher than the motor power. Charging accumulator mode is described in Figure 6. In this mode, fluid from the tank is pumped to the accumulator until it reaches a given pressure value then the pump is shut off. 


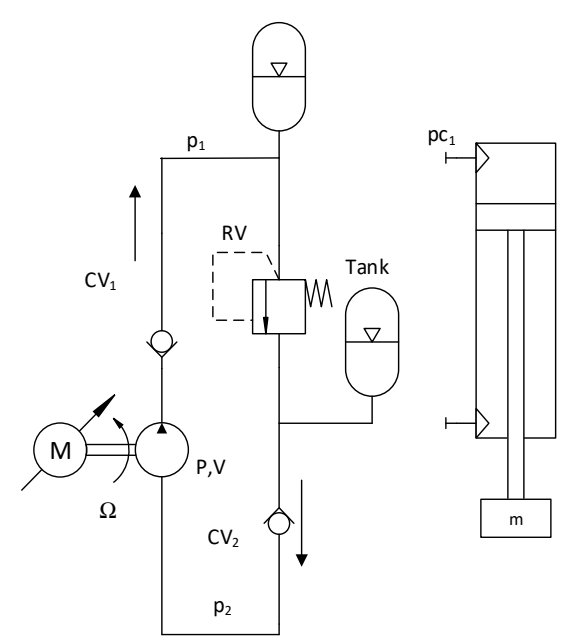

Figure 6. Charging accumulator mode.

The unloading mode is described in Figure 7, in which fluid is circle pumped without any load or the pump is unloading. The cylinder is blocked in any position within its stroke in both the charging and unloading modes.

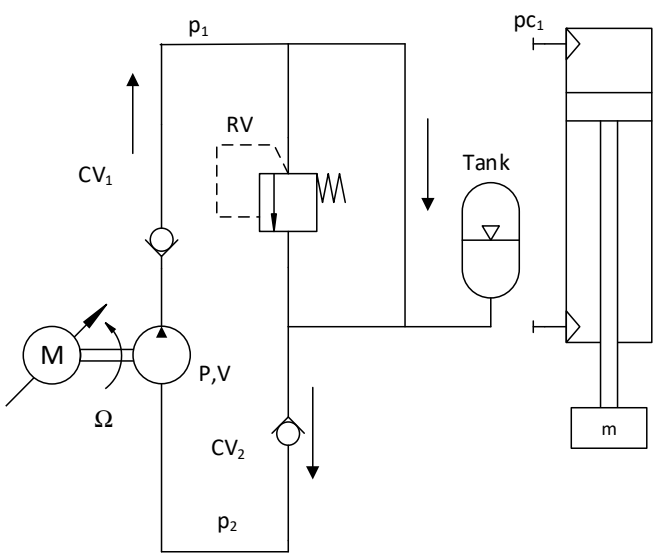

Figure 7. Unloading mode.

Defining velocity and force dimensionless factors $K_{V}, K_{F}$ as expressed in Equations (1) and (2)

$$
\begin{aligned}
& K_{V}=\frac{v}{\omega \cdot r_{0}} \\
& K_{F}=\frac{F}{T / r_{0}}
\end{aligned}
$$

In which, $v[\mathrm{~m} / \mathrm{s}]$ and $F[\mathrm{~N}]$ are velocity and force of the hydraulic cylinder, respectively. $\Omega[\mathrm{rad} / \mathrm{s}]$ and $T[\mathrm{Nm}]$ are speed and torque of the pump, respectively. Defining of $r_{0}[\mathrm{~m}]$ as a radius of the virtual hydraulic pump shaft so that tangential speed and force of the pump shaft at the radius are $\omega \cdot r_{0}$ and $T / r_{0}$, respectively. Therefore, the velocity and force factors express static amplification of outputs of the cylinder over inputs of the pump. These factors and characteristics of the system in different working modes are expressed in Table 2. 
Table 2. Velocity and force factors of the system in different working modes.

\begin{tabular}{|c|c|c|c|c|}
\hline \multirow{2}{*}{ No } & \multirow{2}{*}{ Working Modes } & \multirow{2}{*}{ Characteristics } & \multicolumn{2}{|c|}{ Factors } \\
\hline & & & $K_{V}$ & $K_{F}$ \\
\hline 1 & $\mathrm{NOM}$ & $\begin{array}{l}\text { High force } \\
\text { Low speed }\end{array}$ & $K_{V 1}=\frac{4 \cdot V_{D}}{\pi D^{2} r_{0}}$ & $K_{F 1}=\frac{\pi D^{2} r_{0}}{4 \cdot V_{D}}$ \\
\hline 2 & NIM & $\begin{array}{l}\text { Low force } \\
\text { High speed }\end{array}$ & $K_{V 2}=\frac{4 \cdot V_{D}}{\pi\left(D^{2}-d^{2}\right) r_{0}}$ & $K_{F 2}=\frac{\pi\left(D^{2}-d^{2}\right) r_{0}}{4 \cdot V_{D}}$ \\
\hline 3 & RGOM & $\begin{array}{l}\text { Low force } \\
\text { High speed }\end{array}$ & $K_{V 3}=\frac{4 \cdot V_{D}}{\pi d^{2} r_{0}}$ & $K_{F 3}=\frac{\pi d^{2} r_{0}}{4 \cdot V_{D}}$ \\
\hline 4 & RCOM & Energy recovery in extend direction & $K_{V 1}$ & $-K_{F 1}$ \\
\hline 5 & RCIM & Energy recovery in retract direction & $K_{V 2}$ & $-K_{F 2}$ \\
\hline 6 & RUNO & $\begin{array}{l}\text { The highest force } \\
\text { Low speed }\end{array}$ & $K_{V 1}$ & $K_{F 6}=K_{F 1}\left(\frac{p_{1}}{p_{1}-p_{2}}\right)$ \\
\hline 7 & RUNI & $\begin{array}{l}\text { High force } \\
\text { High speed }\end{array}$ & $K_{V 2}$ & $K_{F 7}=K_{F 2}\left(\frac{p_{1}}{p_{1}-p_{2}}\right)$ \\
\hline 8 & RURG & $\begin{array}{l}\text { High force } \\
\text { High speed }\end{array}$ & $K_{V 3}$ & $K_{F 8}=K_{F 3}\left(\frac{p_{1}}{p_{1}-p_{2}}\right)$ \\
\hline 9 & CAM & Sharing power & 0 & 0 \\
\hline 10 & ULM & Unloading system & 0 & 0 \\
\hline
\end{tabular}

In the table, $V_{D}\left[\mathrm{~m}^{3} / \mathrm{rad}\right]$ is displacement of the pump, $D[\mathrm{~m}]$ and $d[\mathrm{~m}]$ are the bore and the rod diameters of the cylinder, respectively, and $p_{1}$ and $p_{2}$ are values of relative pressure at delivery and suction ports of the pump, respectively.

From Table 2, the normal and regenerative-out modes have velocity factor $K_{V 1}$ and $K_{V 3}$, respectively. It is observed that, the value of $K_{V 3}$ is higher than $K_{V 1}$, so the velocity of the cylinder in the regenerative-out mode is higher than that of the normal-out mode with the same speed of the pump. With the same value of torque at the pump shaft, the cylinder of the system in the normal-out mode can yield a larger force than that of generative-out mode because the value of $K_{F 1}$ is bigger than that of $K_{F 3}$.

The proposed system is able work in different modes with different velocity or force factors. Among them, the highest values of $K_{V}$ and $K_{F}$ are $K_{V 3}$ and $K_{F 6}$, respectively. While, other systems such as EHA has two modes that are normal-out and normal-in modes. As a result, the proposed system reveals some advantages when compared with an EHA system as follows. The system is able to recover energy from the external force in both directions when its works in recovery modes. The size of the hydraulic pump and the electric motor is down which reduces cost of the system when it works in reuse modes. For example, the proposed system works in regenerative mode will has velocity factor $K_{V 3}$ while the EHA has velocity factor $K_{V 1}$. It is known that $K_{V 3}$ is higher than $K_{V 1}$, so the required speed of the pump in the proposed system is lower than that of the EHA. If the speed of the pump is the same, the required displacement of the pump in the proposed system is smaller than that of the EHA.

\subsection{Control Strategy}

A structured controller is suggested for the proposed control strategy, as presented in Figure 8 for controlling the motor to produce the desired cycle. The whole controller consists of a supervisory controller and a position controller. 


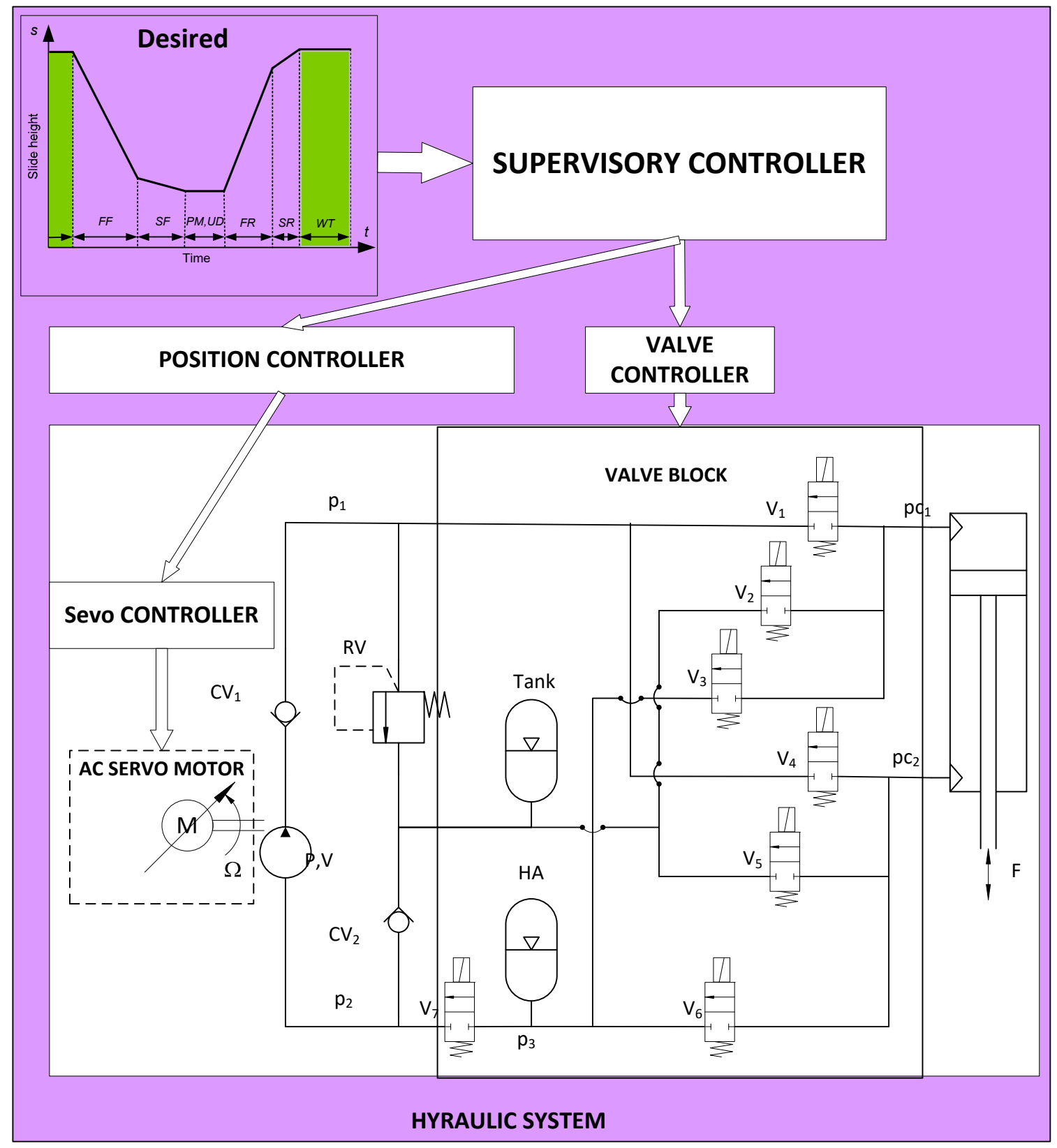

Figure 8. Structure of controller.

The supervisory controller selects the working mode and calculates the pump speed set point. The diagram algorithm for selecting the working mode is described in Figure 9. Then, the working mode is achieved by switching the on/off valves as described in Table 1. In this study, the working mode is selected so that the system has the highest velocity factor or force factor as well it recovers energy of external force for a given cycle. A working mode is selected for each phase and this process is taken place in advance for a given cycle. This strategy is suitable for so many industrial applications such as pressing machines where each pressing profile of a product is usually able to be pre-estimated. This is an open-loop time based control strategy, so a period is used to change the phases of the system. 


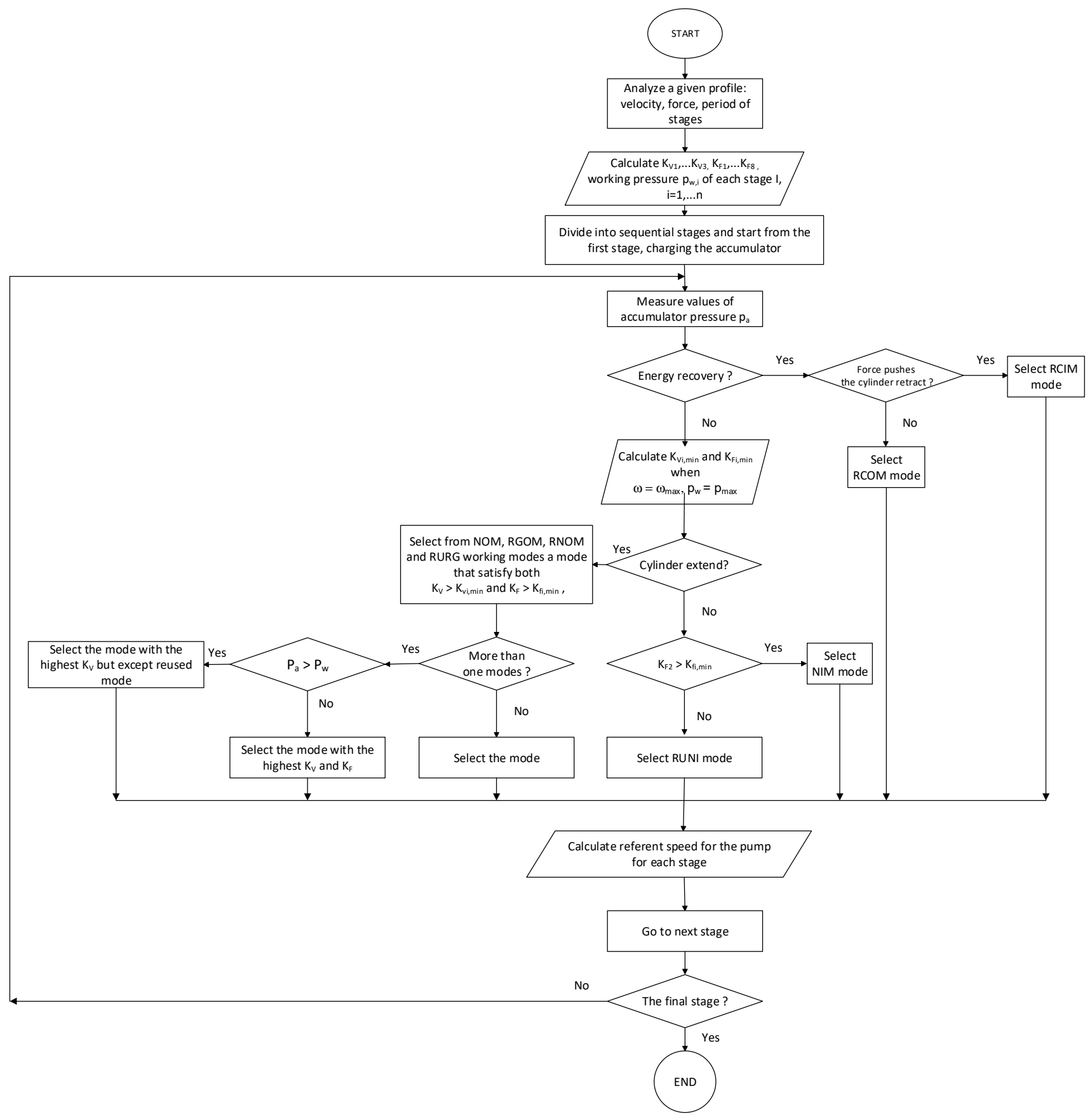

Figure 9. Diagram algorithm for selecting working mode.

The speed set point $\omega_{n}$ of the pump is considered as a steady speed of the pump according to the desired velocity of the cylinder for each phase. When the working mode is selected, a value of $\mathrm{K}_{V}$ is also calculated by using the data in Table 2 . The value of $\omega_{n}$ is calculated by using Equation (1), whereby $v$ is the desired velocity and the value of $K_{V}$ for each phase is shown in Table 2.

The position controller is used for position tracking control of the cylinder. A traditional controller such as a feedforward controller is used for the position controller. The controller consists of a PID algorithm and a feedforward signal, in which parameters of the PID controller such as $K_{P}, K_{I}$ and $K_{D}$ are selected by turning with trials and errors. The speed set point of the pump is used as the feedforward signal. The input of the position controller is the desired cycle and the feedback signal is the position of the cylinder. The output of the controller is sent to the servo controller to control the servo motor. 
Where, $\mathrm{K}_{\mathrm{V}, \mathrm{min}}$ is achieved when the speed of the pump has reached its maximum value and $\mathrm{K}_{\mathrm{F} \text {,min }}$ accounts for working pressure reaches the design limit of the system.

For the purpose of effective evaluation of the control strategy, a typical pressing profile as shown in Figure 10 is brought into analysis, in which RT, FF, SF, PM, FR and SR stands for resting time, fast falling, slow falling, power maintaining, fast returning and slow returning phases in the pressing cycle, respectively. Minimum velocity factor $\mathrm{K}_{V \text {,min }}$ and force factor $\mathrm{K}_{\mathrm{F}, \min }$ of the system are presented in Table 3. It is observed that, $\mathrm{K}_{\mathrm{V} \text {,min }}$ of the system is high in both FF and FR phases to increase productivity. While high requiring of $\mathrm{K}_{\mathrm{F}, \min }$ in $\mathrm{SF}$ and $\mathrm{PM}$ phases to yield the high force at the cylinder rod.

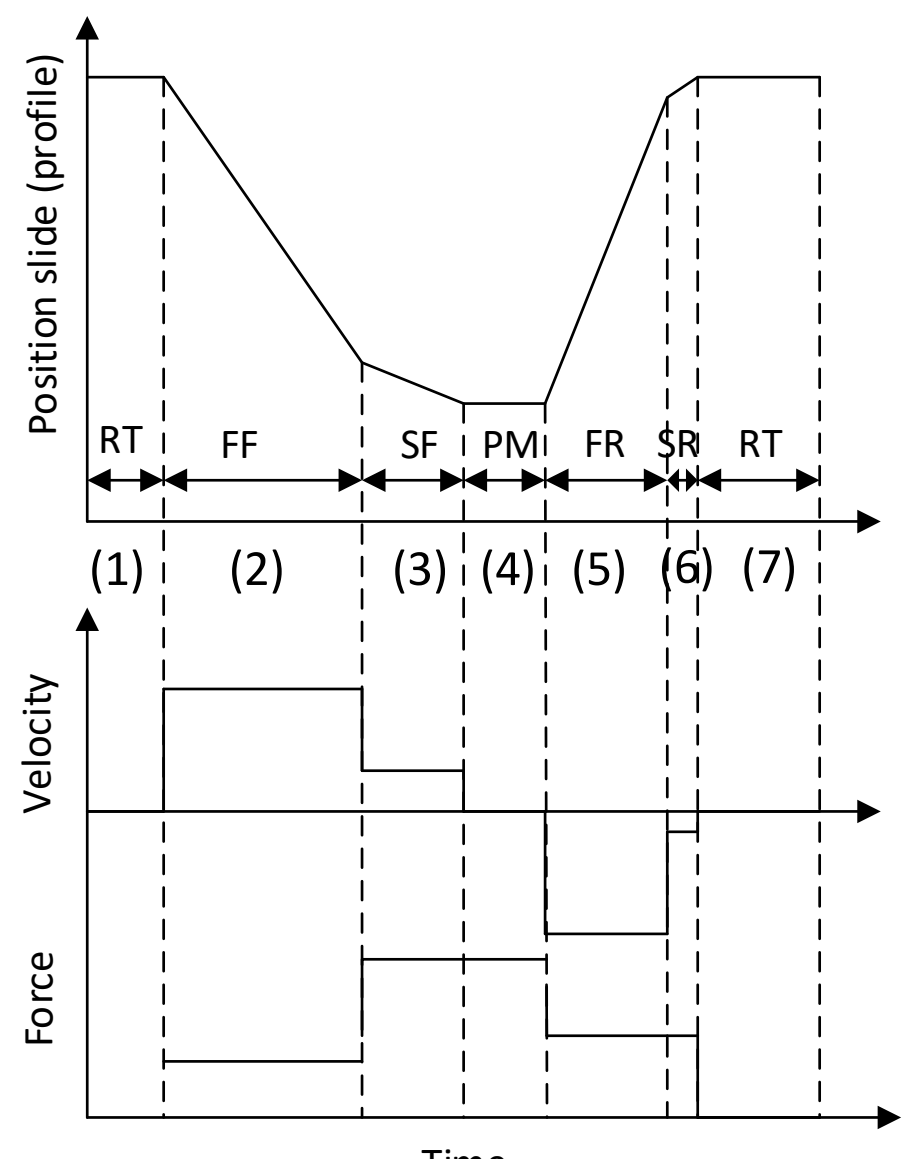

Time

Figure 10. A typical pressing profile.

Table 3. Required velocity factor and force factor of the system.

\begin{tabular}{cccccccc}
\hline \multirow{2}{*}{ Requirement of Factors } & \multicolumn{7}{c}{ Phase in the Pressing Cycle } \\
\cline { 2 - 8 } & RT & FF & SF & PR & FR & SR & RT \\
\hline Phase number & 1 & 2 & 3 & 4 & 5 & 6 & 7 \\
\hline Velocity factor $\mathrm{K}_{\mathrm{V}, \text { min }}$ & NO & HIGH & LOW & LOW & HIGH & LOW & NO \\
\hline Force factor $\mathrm{K}_{\mathrm{F}, \text { min }}$ & NO & LOW & HIGH & HIGH & LOW & LOW & NO \\
\hline
\end{tabular}

To finish the pressing cycle, three control strategies are suggested including proposed strategy PS, not recovery strategy (NRS) and EHA strategy without energy recovery (EHA). The three strategies are described in Table 4. Among them, The EHA is considered as basic strategy that satisfies requirements of both high velocity and force for 2nd and 4th phases of the cycle. Besides, the EHA strategy is not taking place energy recovery in 5th and 6th phases of the cycle. On the other hand, the PS strategy is used diagram shown in 
Figure 9 to select working modes. Therefore, energy of external load is recovered during returning phases (6th and 7th phases) of the cycle. Moreover, the accumulator is used for storing energy in 1st and 7th phases and reusing in 3rd and 4th phases. The only difference between the NRS and the PS strategy is that the system does not recover energy from external load in 5th and 6th phases of the pressing cycle.

Table 4. Control strategies.

\begin{tabular}{|c|c|c|c|c|c|c|c|c|c|c|}
\hline \multirow{2}{*}{ Order } & \multirow{2}{*}{$\begin{array}{c}\text { Pressing } \\
\text { Phases }\end{array}$} & \multicolumn{3}{|c|}{ PS } & \multicolumn{3}{|c|}{ NRS } & \multicolumn{3}{|c|}{ EHA } \\
\hline & & $\mathbf{K}_{\mathbf{V}}$ & $\mathbf{K}_{\mathbf{F}}$ & Working Modes & $\mathbf{K}_{\mathbf{V}}$ & $\mathbf{K}_{\mathbf{F}}$ & Working Modes & $\mathbf{K}_{\mathbf{V}}$ & $\mathbf{K}_{\mathbf{F}}$ & Working Modes \\
\hline 1 & RT & 0 & 0 & CAM & 0 & 0 & CAM & 0 & 0 & ULM \\
\hline 2 & $\mathrm{FF}$ & $\mathrm{K}_{\mathrm{V} 3}$ & $\mathrm{~K}_{\mathrm{F} 3}$ & RGOM & $\mathrm{K}_{\mathrm{V} 3}$ & $\mathrm{~K}_{\mathrm{F} 3}$ & RGOM & $\mathrm{K}_{\mathrm{V} 1}$ & $\mathrm{~K}_{\mathrm{F} 1}$ & NOM \\
\hline 3 & SF & $\mathrm{K}_{\mathrm{V} 1}$ & $\mathrm{~K}_{\mathrm{F} 6}$ & RUNO & $\mathrm{K}_{\mathrm{V} 1}$ & $\mathrm{~K}_{\mathrm{F} 6}$ & RUNO & $\mathrm{K}_{\mathrm{V} 1}$ & $\mathrm{~K}_{\mathrm{F} 1}$ & $\mathrm{NOM}$ \\
\hline 4 & PM & $\mathrm{K}_{\mathrm{V} 1}$ & $\mathrm{~K}_{\mathrm{F} 6}$ & RUNO & $\mathrm{K}_{\mathrm{V} 1}$ & $\mathrm{~K}_{\mathrm{F} 6}$ & RUNO & $\mathrm{K}_{\mathrm{V} 1}$ & $\mathrm{~K}_{\mathrm{F} 1}$ & $\mathrm{NOM}$ \\
\hline 5 & FR & $\mathrm{K}_{\mathrm{V} 2}$ & $-\mathrm{K}_{\mathrm{F} 2}$ & RCIM & $\mathrm{K}_{\mathrm{V} 2}$ & $\mathrm{~K}_{\mathrm{F} 2}$ & NIM & $\mathrm{K}_{\mathrm{V} 2}$ & $\mathrm{~K}_{\mathrm{F} 2}$ & NIM \\
\hline 6 & SR & $\mathrm{K}_{\mathrm{V} 2}$ & $-\mathrm{K}_{\mathrm{F} 2}$ & RCIM & $\mathrm{K}_{\mathrm{V} 2}$ & $\mathrm{~K}_{\mathrm{F} 2}$ & NIM & $\mathrm{K}_{\mathrm{V} 2}$ & $\mathrm{~K}_{\mathrm{F} 2}$ & NIM \\
\hline 7 & RT & 0 & 0 & ULM & 0 & 0 & ULM & 0 & 0 & ULM \\
\hline
\end{tabular}

Within the PS strategy, the system has $\mathrm{K}_{\mathrm{V} 3}$ in 2nd phase and it has $\mathrm{K}_{\mathrm{F} 6}$ in 3rd and 4th phases. As a result, the system is the fastest in 2nd phase and the strongest in both 3rd and 4th phases when comparison with EHA control strategy. Moreover, the $\mathrm{K}_{\mathrm{F}}$ of the system is $-\mathrm{K}_{\mathrm{F} 2}$ in both 5 th and 6th phases, which indicates that the system is able to recover energy from the external load. The general characteristics of the three control strategies for the pressing profile are described in Table 5.

Table 5. General characteristics of the three control strategies.

\begin{tabular}{|c|c|c|c|c|}
\hline \multirow{2}{*}{ No } & \multirow{2}{*}{ Pressing Phase } & \multicolumn{3}{|c|}{ Characteristics of the Three Control Strategies } \\
\hline & & PS & NRS & EHA \\
\hline 1 & RT & $\begin{array}{l}\text { No velocity, no force, low } \\
\text { input power }\end{array}$ & $\begin{array}{l}\text { No velocity, no force, low } \\
\text { input power }\end{array}$ & $\begin{array}{l}\text { No velocity, no force, no input } \\
\text { power }\end{array}$ \\
\hline 2 & FF & High velocity, low force & High velocity, low force & Low velocity, high force \\
\hline 3 & SF & $\begin{array}{l}\text { Low velocity, high force, low } \\
\text { pump torque }\end{array}$ & $\begin{array}{l}\text { Low velocity, high force, low } \\
\text { pump torque }\end{array}$ & $\begin{array}{l}\text { Low velocity, high force, high } \\
\text { pump torque }\end{array}$ \\
\hline 4 & PM & $\begin{array}{l}\text { Low velocity, high force, low } \\
\text { pump torque }\end{array}$ & $\begin{array}{l}\text { Low velocity, high force, low } \\
\text { pump torque }\end{array}$ & $\begin{array}{l}\text { Low velocity, high force, high } \\
\text { pump torque }\end{array}$ \\
\hline 5 & FR & $\begin{array}{l}\text { Energy recovery, high } \\
\text { velocity, low force }\end{array}$ & $\begin{array}{l}\text { No energy recovery, high } \\
\text { velocity, low force }\end{array}$ & $\begin{array}{l}\text { No energy recovery, high } \\
\text { velocity, low force }\end{array}$ \\
\hline 6 & SR & $\begin{array}{l}\text { Energy recovery, high } \\
\text { velocity, low force }\end{array}$ & $\begin{array}{l}\text { No energy recovery, high } \\
\text { velocity, low force }\end{array}$ & $\begin{array}{l}\text { No energy recovery, high } \\
\text { velocity, low force }\end{array}$ \\
\hline 7 & RT & $\begin{array}{l}\text { No velocity, no force, no } \\
\text { input power }\end{array}$ & $\begin{array}{l}\text { No velocity, no force, no } \\
\text { input power }\end{array}$ & $\begin{array}{c}\text { No velocity, no force, no input } \\
\text { power }\end{array}$ \\
\hline
\end{tabular}

\section{Modeling of the System in AMESim Software}

For the purpose of verifying the energy saving ability of the system, a model of the system is built in AMESim software as presented in Figure 11. The parameters of the model are described in Table 6 in which these components are modeled based on the following assumed conditions. 


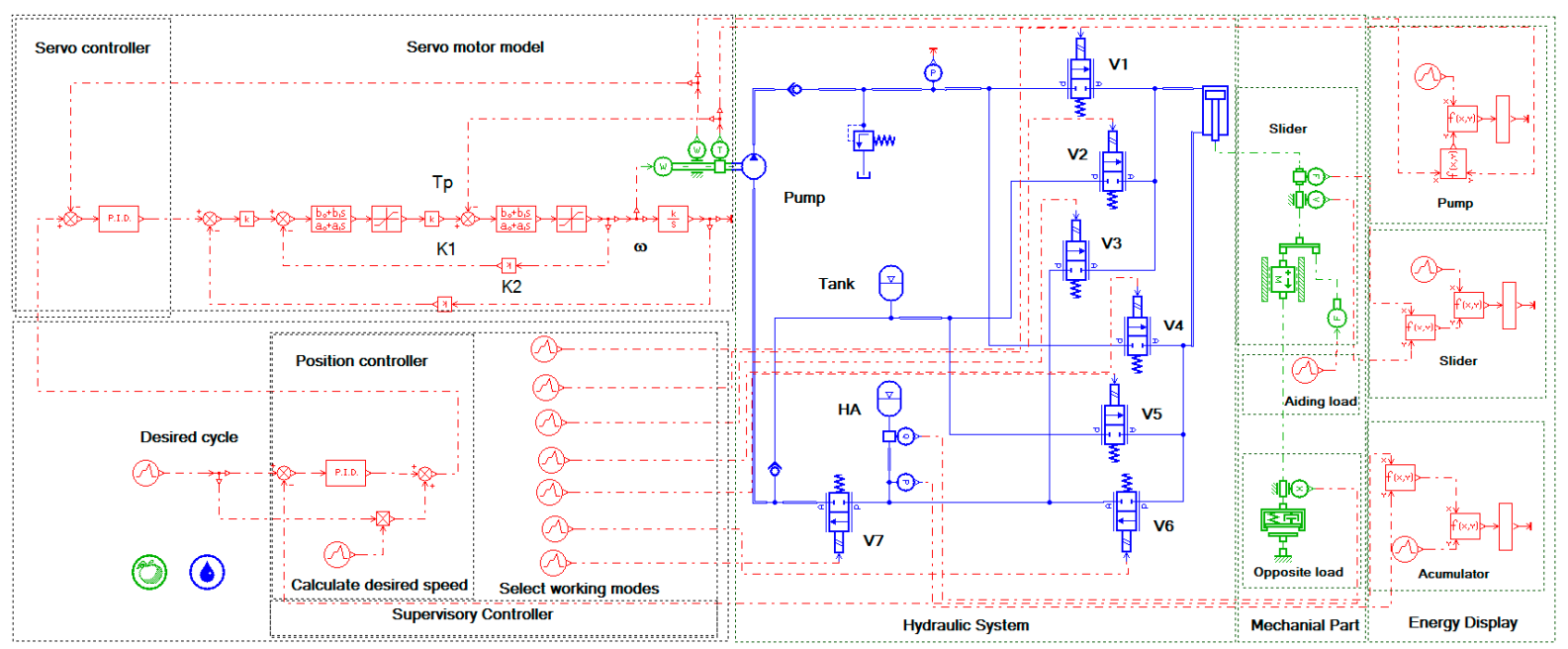

Figure 11. AMESim model of the system.

Table 6. Parameters of the system.

\begin{tabular}{|c|c|c|c|c|}
\hline No & Equipment & Parameters & Values & Unit \\
\hline \multirow{6}{*}{1} & \multirow{6}{*}{ Hydraulic pump } & Displacement (V) & $1.6 \times 10^{-6}$ & $\mathrm{~m}^{3} / \mathrm{rad}$ \\
\hline & & Volumetric efficiency in pump mode & \multirow{2}{*}{$\begin{array}{l}\text { as a function of speed } \\
\text { end pressure }\end{array}$} & - \\
\hline & & Mechanical efficiency in pump mode & & \\
\hline & & Volumetric efficiency in motor mode & \multirow{2}{*}{$\begin{array}{l}\text { as a function of speed } \\
\text { end pressure }\end{array}$} & - \\
\hline & & Mechanical efficiency in motor mode & & \\
\hline & & Moment of inertia & 0.012 & $\mathrm{~kg} \cdot \mathrm{m}^{2}$ \\
\hline \multirow{2}{*}{2} & \multirow{2}{*}{ Hydraulic valve } & Nominal flow rate & $10^{-3}$ & $\mathrm{~m}^{3} / \mathrm{s}$ \\
\hline & & Sifting time & 20 & $\mathrm{~ms}$ \\
\hline \multirow{6}{*}{3} & \multirow{6}{*}{ Hydraulic cylinder } & Bore diameter $\mathrm{D}$ & $6 \times 10^{-2}$ & $\mathrm{~m}$ \\
\hline & & Rod diameter d & $4.5 \times 10^{-3}$ & $\mathrm{~m}$ \\
\hline & & Max Stroke & 0.3 & $\mathrm{~m}$ \\
\hline & & Dead volume at port 1 end & $5 \times 10^{-5}$ & $\mathrm{~m}^{3}$ \\
\hline & & Dead volume at port 2 end & $5 \times 10^{-5}$ & $\mathrm{~m}^{3}$ \\
\hline & & Leakage coefficient & $10^{-7}$ & $\mathrm{~m}^{3} / \mathrm{s} / \mathrm{bar}$ \\
\hline \multirow{2}{*}{4} & \multirow{2}{*}{ Hydraulic accumulator } & Pre-charge pressure & $60 \times 10^{5}$ & $\mathrm{~Pa}$ \\
\hline & & Volume & $6 \times 10^{-3}$ & $\mathrm{~m}^{3}$ \\
\hline \multirow{5}{*}{5} & \multirow{5}{*}{ Slider } & Mass & 100 & $\mathrm{~kg}$ \\
\hline & & External load & 30 & $\mathrm{kN}$ \\
\hline & & Viscous friction coefficient & 0.1 & $\mathrm{~N} /(\mathrm{m} / \mathrm{s})$ \\
\hline & & Coulomb force & 250 & $\mathrm{~N}$ \\
\hline & & Stiction force & 800 & $\mathrm{~N}$ \\
\hline 6 & Spring & Stiffness & $12 \times 10^{4}$ & $\mathrm{~N} / \mathrm{m}$ \\
\hline \multirow{3}{*}{7} & \multirow{3}{*}{ Pipe } & Diameter & $12.8 \times 10^{-3}$ & $\mathrm{~m}$ \\
\hline & & Bulk modulus & $8 \times 10^{9}$ & $\mathrm{~Pa}$ \\
\hline & & Length & $0.5-1.5$ & $\mathrm{~m}$ \\
\hline 8 & Relief valve & Setting pressure & 15 & $\mathrm{MPa}$ \\
\hline
\end{tabular}




\subsection{Hydraulic Pump}

The model of the hydraulic pump is shown in Figure 11, in which the pump is driven by the AC servo motor via the way that the speed signal output of the motor model is connected to the speed signal of the pump.

The volumetric and mechanical efficiencies of a pump depend on pump speed and different pressure between two ports of the pump [1]. These efficiencies can be achieved from the data sheet of the pump. In this case, the values of the mechanical and volumetric efficiencies of the pump vary in two intervals (0.8-0.93) and (0.63-0.95), respectively. When the value of the pressure $p_{2}$ is higher than that of the value of $p_{1}$, the hydraulic pump works as a motor. When the pump works in the motor mode, the system recovers energy from the external load. In this study, the values of the mechanical and volumetric efficiencies of the pump in the motor mode vary in two intervals (0.7-0.9) and (0.6-0.9), respectively. In AMESim software, these efficiencies are converted into form of table inputs.

\subsection{Hydraulic Accumulator}

The hydraulic accumulator was modeled with high orders and in multi-domains including the gas flow rate, gas pressure and temperature of the accumulator [17]. For simplicity, a model of the accumulator with the pressure and volume is used in order to evaluate energy recovery potential of system. The energy loss model of the accumulator due to thermal is neglected in the condition that the temperature of the accumulator is not much changed.

\subsection{Hydraulic Cylinder and Slider}

In this paper, the friction of the cylinder is lumped with friction of the slider. The external load appears in the SF and PM phases of the pressing cycle. The values of slider friction parameters shown in Table 6 are achieved by the literature review and modified from the prototype model $[28,29]$. The model of the hydraulic cylinder is built based on the compressibility of the fluid in the cylinder chambers, leakage, damping coefficient on end stops and deformation on end stops at which the damping rate is fully effective. The model of HJ020 in AMESim is used for the cylinder and its parameters are described in Table $6[1,9]$.

\subsection{Hydraulic Valves}

In this study, directional control valves are used. The nominal flow rate and sifting time are the considered parameters, as described in Table 6. For this system, the phase change is performed by switching the on/off directional control valve. The model of the on/off valve can be used a proportional valve model, as shown in Figure 11, as it has the same performance with step input.

\subsection{Hydraulic Pipes}

The hydraulic pipe model is used as a compressibility and friction hydraulic pipe model in AMESim in which the bulk modulus, length and diameter of the pipes are considered, as in Table 6 . The pipe length varies depending on its connected position. Connections between the directional control valve are used in the simple direct model because the volumes under pressure are low and the fluid compressibility does not introduce significant dynamics. 


\subsection{Energy Model}

In the first study, only the energy flow in the hydraulic system is investigated in order to neglect the effect of the efficiency of the electric motor as well the servo controller. The pump efficiencies are studied in depth because they depend on the torque and the speed of the pump. As a result, the supplying energy is defined as the mechanical energy at the pump shaft level. The energy in the display block shows the supplying energy of the pump, slider and the accumulator. This energy is estimated by Equations (3)-(5).

The hydraulic energy stored in the accumulator $E_{a}$ is expressed by Equation (3), and the accumulator energy is considered as the recovery energy for the PS control strategy.

$$
E_{a}=\int_{t_{0}}^{t_{1}} p_{a} q_{a} d t+\int_{t_{4}}^{t_{6}} p_{a} q_{a} d t
$$

The supplying energy to the pump shaft $E_{m}$ is expressed by Equation (4):

$$
E_{m}=\int_{t_{0}}^{t_{7}}|T \cdot \omega| d t
$$

The consumed energy of the hydraulic system to finish a cycle $E_{r}$ is expressed by Equation (5):

$$
E_{r}=E_{m}-E_{a}
$$

In which, $t_{0}, t_{1}, t_{4}$ and $t_{7}$ are time at the beginning and the ending of resting and returning phases, respectively; $p_{a}$ is pressure and $q_{a}$ is flow rate to the accumulator.

\subsection{AC Servo Motor and Servo Controller Models}

In this study, a model using signal for both the AC servo motor and its servo controller is reconstructed because the control of the motor is not implemented in the details. Moreover, only the speed response of the servomotor and its controller is studied, so a simple block diagram of the motor model is used [30-32], as shown in Figure 11.

In this diagram $-R_{S}, R_{R}$ : stator and rotor resistances $(\Omega) ; L_{S}, L_{R}$ : stator and rotor inductances $(\mathrm{mH}) ; K_{1}, K_{2}$ : motor constants $(\mathrm{Nm} / \mathrm{V}, \mathrm{Nms} / \mathrm{rad}) ; V_{s}$ : control field voltage in stator; c: damping resistance of the load (Nms/rad); $\theta_{m}$ : angular position of the motor $(\mathrm{rad}) ; \theta_{m R}:$ reference angular position of the motor (rad), $\dot{\theta}_{m}$ : angular velocity of the motor $(\mathrm{rad} / \mathrm{s}) ; \mathrm{J}_{\mathrm{m}}, \mathrm{Jg}, \mathrm{J}_{\mathrm{p}}$ : moment of inertias of the motor, gearbox and pump; torque constant $K_{1}(\mathrm{Nm} / \mathrm{V})$ and $K_{2}(\mathrm{Nms} / \mathrm{rad})$ are speed constant; $\ddot{\theta}_{m}$ : angular acceleration of the motor $\left(\mathrm{rad} / \mathrm{s}^{2}\right)$; Values of these parameters are given as $\mathrm{J}_{\mathrm{m}}=0.012 \mathrm{~kg} \cdot \mathrm{m}^{2}, \mathrm{~J}_{\mathrm{p}}=0.005 \mathrm{~kg} \cdot \mathrm{m}^{2}$, $K_{1}=8.43 \times 10^{-3} \mathrm{Nm} / \mathrm{V}, K_{2}=7.03 \times 10^{-3} \mathrm{Nms} / \mathrm{rad}, \mathrm{L}_{\mathrm{s}}=\mathrm{L}_{\mathrm{R}}=50 \mathrm{mH}, \mathrm{R}_{\mathrm{S}}=\mathrm{R}_{\mathrm{R}}=3.6 \Omega$, and, limit speed and torque are of $3000 \mathrm{rpm}$ and $25 \mathrm{Nm}$, respectively.

The servo controller is used a PID algorithm and these parameters of the servo controller $\mathrm{K}_{\mathrm{Is}}, \mathrm{K}_{\mathrm{Ps}}$ and $\mathrm{K}_{\mathrm{Ds}}$ are selected by turning with trials and errors. The tuning values are found as $\mathrm{K}_{\mathrm{p}}=25, \mathrm{~K}_{\mathrm{V}}=12$, and $\mathrm{K}_{\mathrm{i}}=3$, respectively.

\section{Simulation Results}

In this simulation, three control strategies that are the PS, the NRS and the EHA are brought into simulation. Parameters of the cycle are described in Table 7 in which speed of the pump is controlled by servo controller. 
Table 7. Parameters of pressing cycle.

\begin{tabular}{cccccccc}
\hline Pressing Phases & RT & FF & SF & PM & FR & SR & RT \\
\hline Phase numbers & 1 & 2 & 3 & 4 & 5 & 6 & 7 \\
\hline Period (second) & 1 & 2 & 2 & 2 & 2 & 1 & 1 \\
\hline External force (kN) & 0 & 0 & 30 & 30 & 0 & 0 & 0 \\
\hline Speed of the pump (rpm) & & & & & & & \\
\hline PS strategy & 500 & 400 & 80 & 0 & 400 & 90 & 0 \\
\hline NRS & 500 & 400 & 80 & 0 & 400 & 90 & 0 \\
\hline EHA & 500 & 800 & 160 & 0 & 400 & 90 & 0 \\
\hline
\end{tabular}

\subsection{Open Response}

The response of speed of the motor with the servo controller in EHA mode in respect to the multi-step input is shown in Figure 12a. To finish a cycle, the speed of the motor starts from zero and finishes also at zero speed after the 12th second. It is observed that, the output of the model plotted by the dashed line is well tracked by the reference plotted by the continuous line. The error plotted by the dotted line is acceptable with the steady state error at zero.

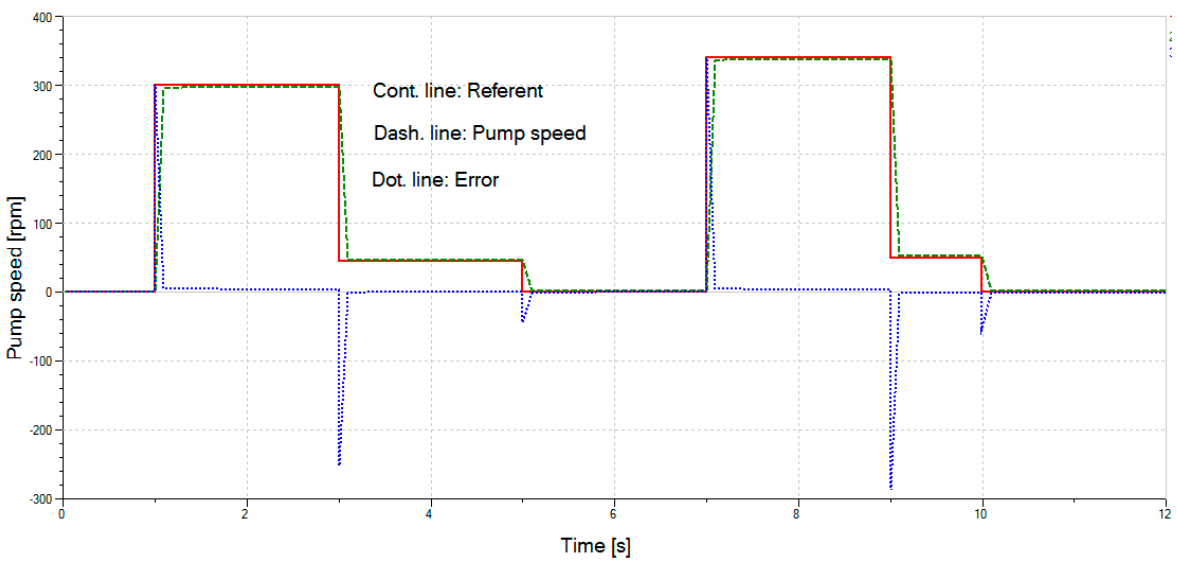

(a)

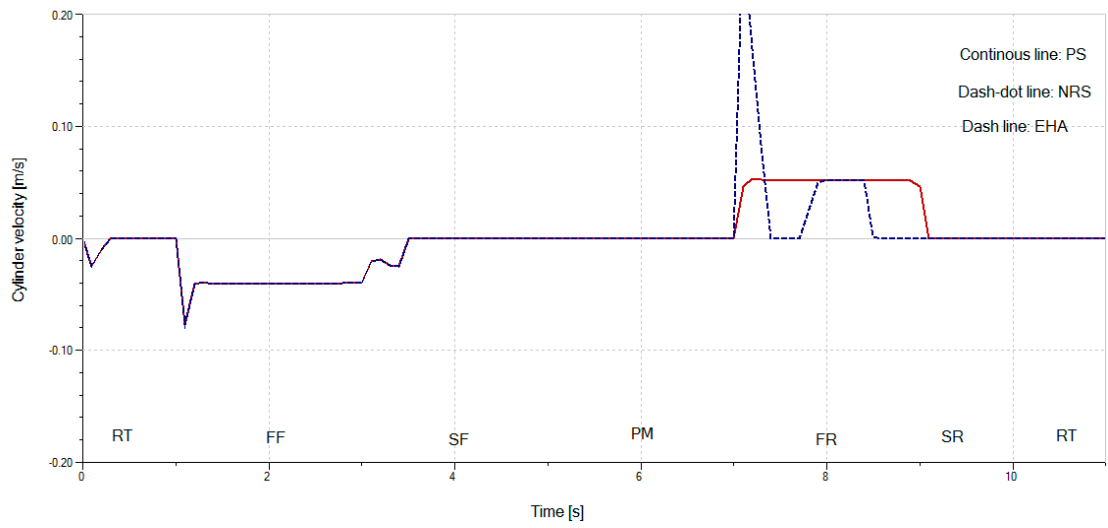

(b)

Figure 12. Cont. 


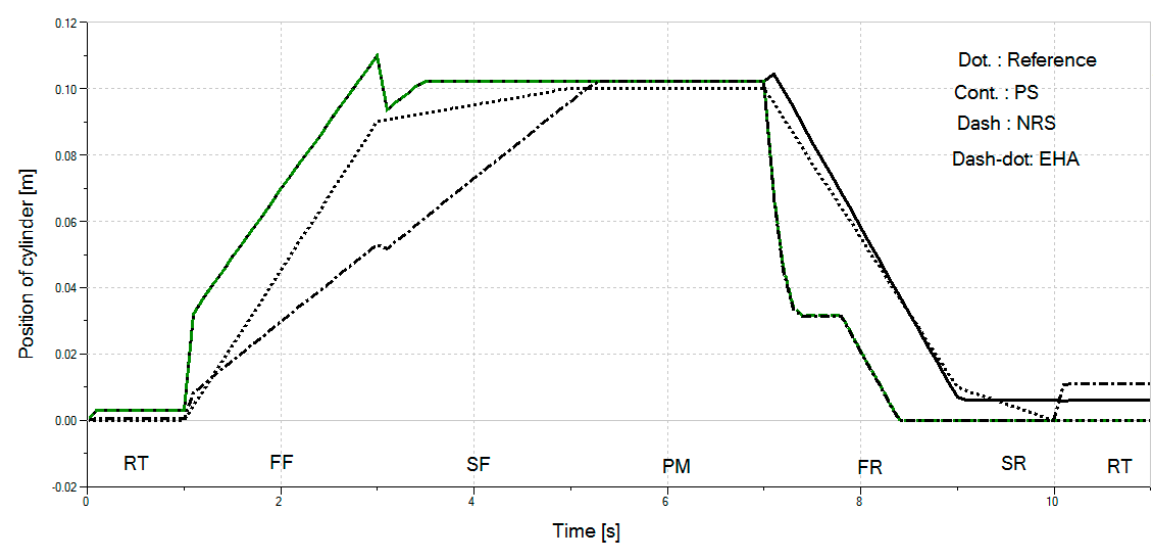

(c)

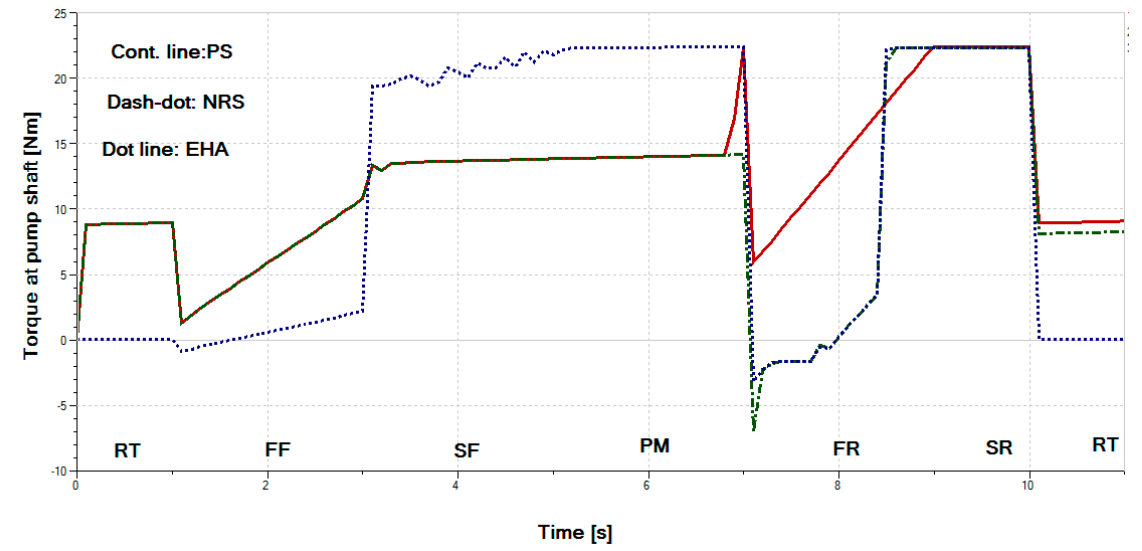

(d)

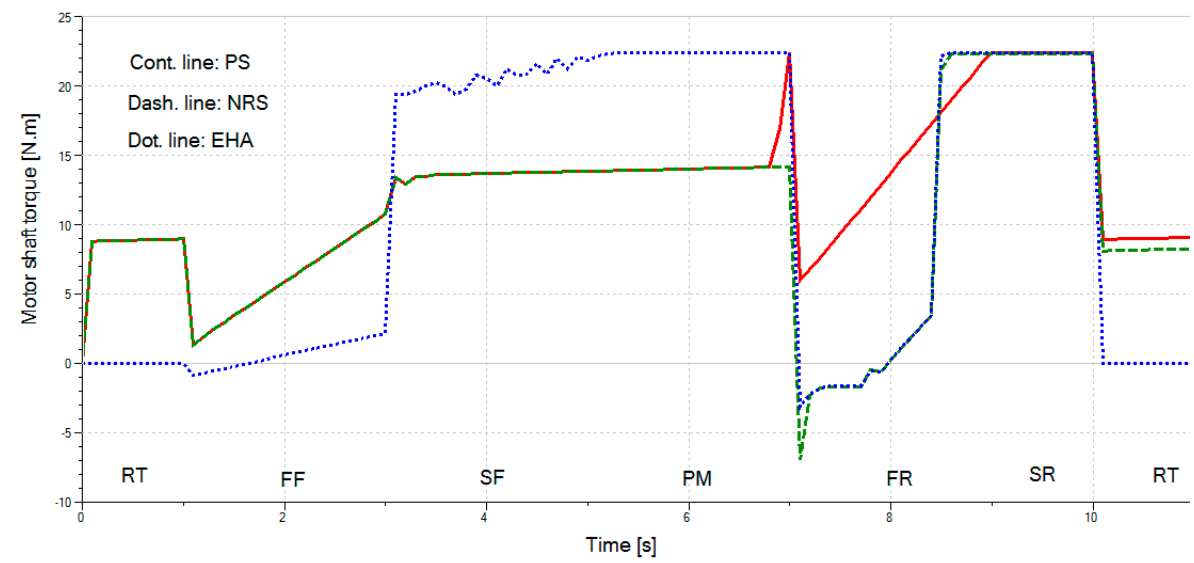

(e)

Figure 12. (a) Pump speed response in EHA mode; (b) cylinder velocity open response; (c) cylinder position open response; (d) pressure at pump ports; (e) torque at pump shaft.

The open response of the cylinder according to the step input for three control strategies are presented in Figure 12b, in which the speed of the pump is $400 \mathrm{rpm}$, and the time period for each phase is described in Table 7. It is observed that, the velocity of the cylinder in the PS or the NRS strategy is much higher than that value for the EHA strategy within the FF phase. There are notches when the changing phases, and its value is about $15 \%$ according with the PS strategy. There is vibration in the PM stage within the EHA strategy, that is an effect of the external force. 
The notch occurred at the 7th second for both the NRS and the EHA strategies while not for the PS strategy, which is the cause of the reload force of the spring. For both the EHA and NRS strategies, the flow outlet of the cylinder goes directly to the tank without any throttling control during returning phases. Therefore, the value of the speed for the EHA or NRS strategy is so high at the beginning of the FR phase when compared with that value for the PS strategy. For the PS strategy, the reload force is partially compensated by a hydraulic force due to pressure in the accumulator. As a result, the position of the cylinder that is shown in Figure 12c is different within three strategies. The cylinder reaches the value of $0.1 \mathrm{~m}$ in about $2 \mathrm{~s}$ for the PS or the NRS strategy, while that value is $4 \mathrm{~s}$ for the EHA strategy. Notches in the position occur and the values of them are about $20 \%$ at the 3rd second. Moreover, there is remained steady position error in the PM and the ending phases of the cycle.

The operating pressure of the system for the PS strategy is higher than that value for the EHA strategy in the FF and FR phases and the cause of the regenerative and recovery operating modes, respectively. The pressure of the suction port of the pump for the PS strategy is higher than that value for the EHA strategy in SF and PM phases. That is the result of the reused operating mode, where the pressure of the accumulator charges to the suction port of the pump. Therefore, torque at the pump shaft for the PS strategy is lower than that value for the EHA strategy.

Torque of the shaft pump in different control strategies is shown in Figure 12e. It is observed that, torque of pump shaft for the NRS or the EHA strategy is low in FR phase cause of reload force of the spring. During this time, the accumulator is charging or the pressure of the cylinder end is increasing for the PS strategy. As a result, the operating pressure or torque is high in this phase.

Parameters of the accumulator are shown in Figure 13 that are pressure and flow rate of fluid and volume of gas in the accumulator. Pressure and volume of hydraulic fluid in the accumulator are presented in Figure 13a,b, respectively. At the beginning of the cycle, the gas pressure is 60 bar and it raises to 66 bar at the end the cycle, while the volume of fluid is raised from $0 \mathrm{~L}$ to $5.5 \mathrm{~L}$ or the volume of fluid increases from 0 to $0.5 \mathrm{~L}$, respectively.

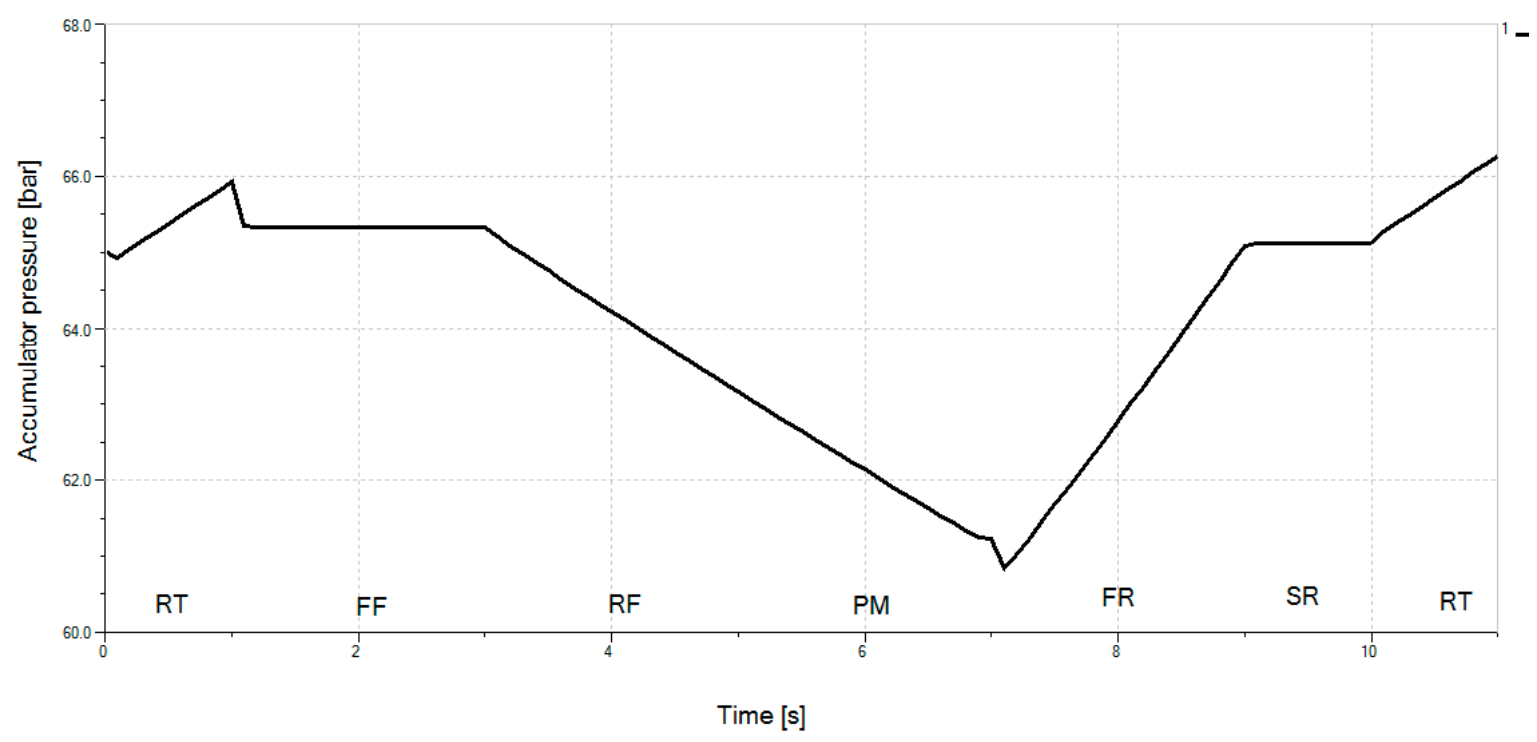

(a)

Figure 13. Cont. 


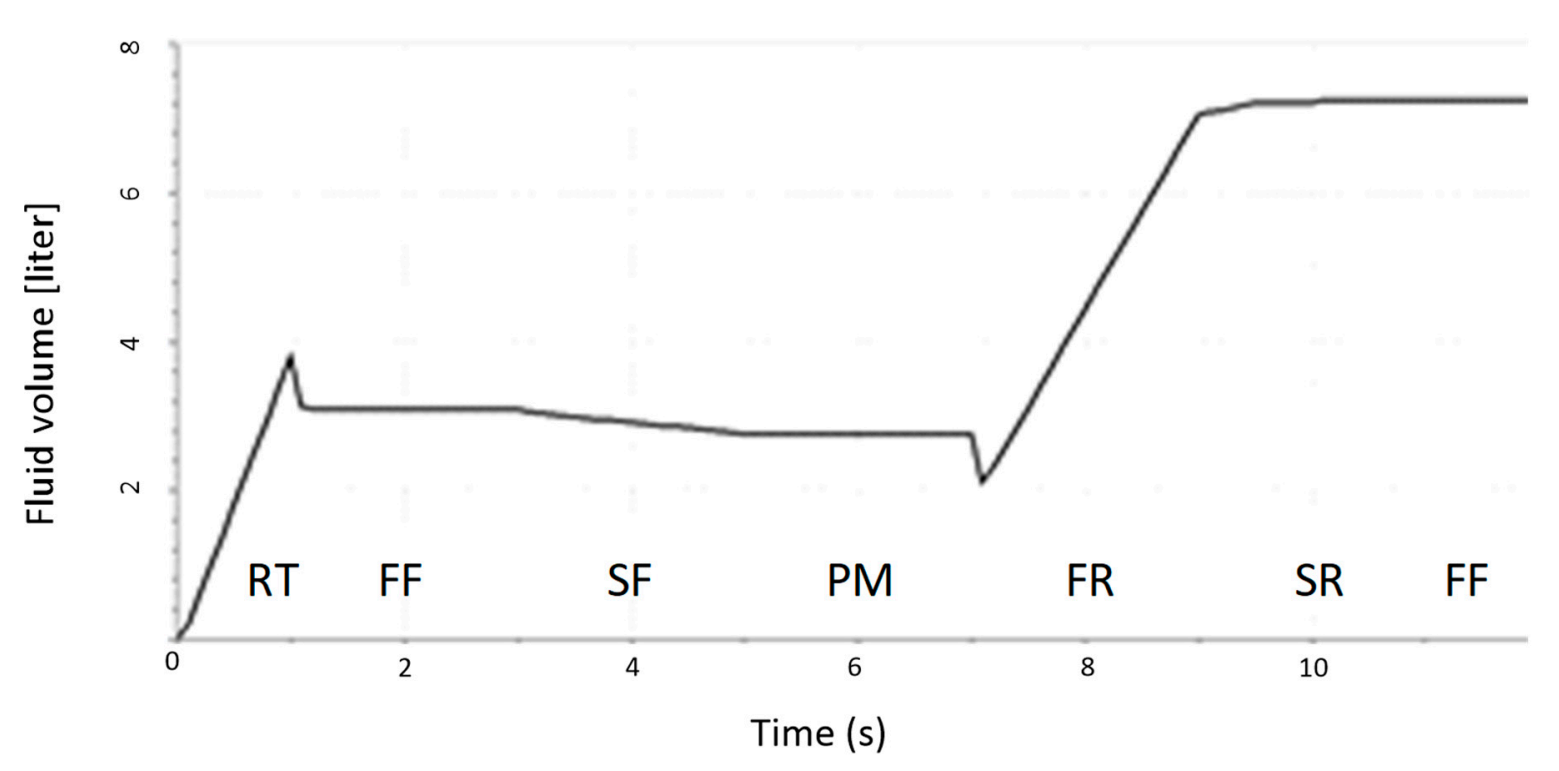

(b)

Figure 13. (a) Pressure of the accumulator; (b) hydraulic volume of the accumulator.

\subsection{Energy Recovery Ability of the System for PS Strategy}

From the open response, it is observed that a closed position controller of the system for every control strategy is needed. The position of the controller is described in the control strategy section. The parameters $\mathrm{K}_{\mathrm{P}}, \mathrm{K}_{\mathrm{I}}$ and $\mathrm{K}_{\mathrm{D}}$ are selected by turning with trials and errors and the feedforward signal is used the estimated value of the motor speed as described in Table 7. Results of the cylinder position response for the three control strategies to a pressing cycle are shown in Figure 14a, in which the speed of the cylinder in the FF phase is very fast for both the NRS and EHA strategies. The system for both EHA and NRS strategies is not able to reduce these speeds because the outlet port of the cylinder is directly connected to the tank. As a result, the cylinder is pushed by the spring force to starting level and the pump is only delivering flow rate with low pressure. However, the position errors in the SF and PM phases are maintained at a low value for the three strategies. Therefore, the system is brought into energy consumption assessment for this cycle.

The energy consumption of the system in the cycle is shown in Figure 14b, in which the system consumes $700 \mathrm{~J}$ to finish the pressing cycle for the PS strategy. While the system consumes $854 \mathrm{~J}$ and $840 \mathrm{~J}$ for the pressing cycle for both the NRS and the EHA strategies, respectively. Therefore, the proposed system is more saving energy than a typical without energy recovery EHA system about $20 \%$ for the pressing cycle with recoverable external force. In FR and SR phases, consumed energy of the system for PS strategy is reduced which implies that the system is recovering in theses phases.

The energy flow of the system for PS strategy in the cycle is shown in Figure 14c. It can be observed that energy is always supplied from the motor, in which that energy is used to charge the accumulator in RT phase while that energy is used to overcome external load and push the cylinder out during FF and SF phases. On the other hand, the motor still supplies energy during the recovery phases and the recovery energy is stored in the accumulator instead of electronics drive as a traditional energy recovery EHA system. Moreover, it has also to be mentioned that the energy losses in the electronic drive are neglected and efficiencies of the pump are included.

The total energy is supplied to the pump is $2.143 \mathrm{~kJ}$, but the accumulator is stored $1.435 \mathrm{~kJ}$. Therefore, the system consumes $700 \mathrm{~J}$ to finish the cycle. During RT phase, the supplying and the accumulator or recovery energy are nearly the same. The consumed 
increases in FF and SF phases but decrease in FR and SR phases, which is proved that the system recovers during the returning phases of the cycle.

Figure 14d shows energy flow of the system for PS strategy in FR and SR phases of the cycle, in which the energy supplied from the motor is lower than energy stored in the accumulator. Which indicates that the system recovers energy of the spring in these phases.

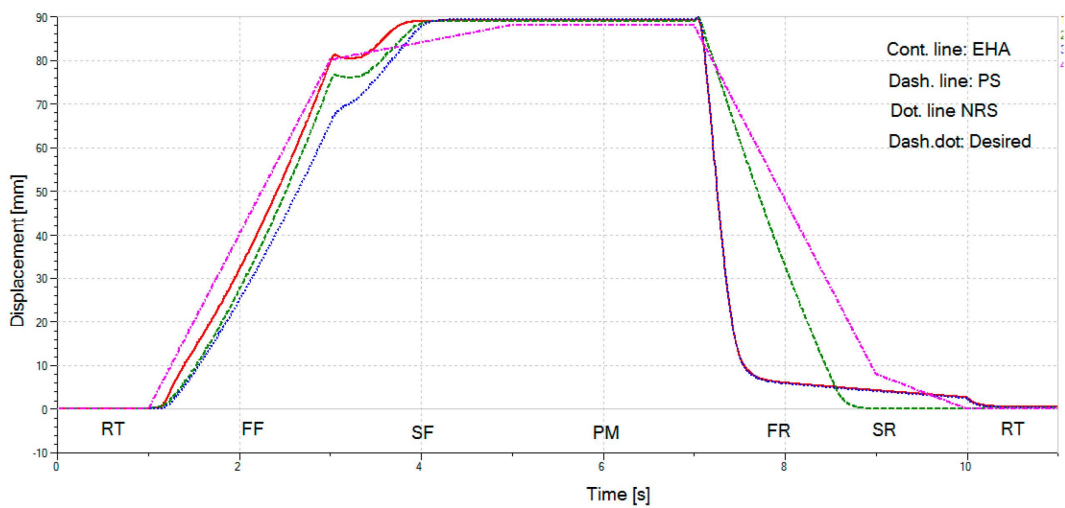

(a)

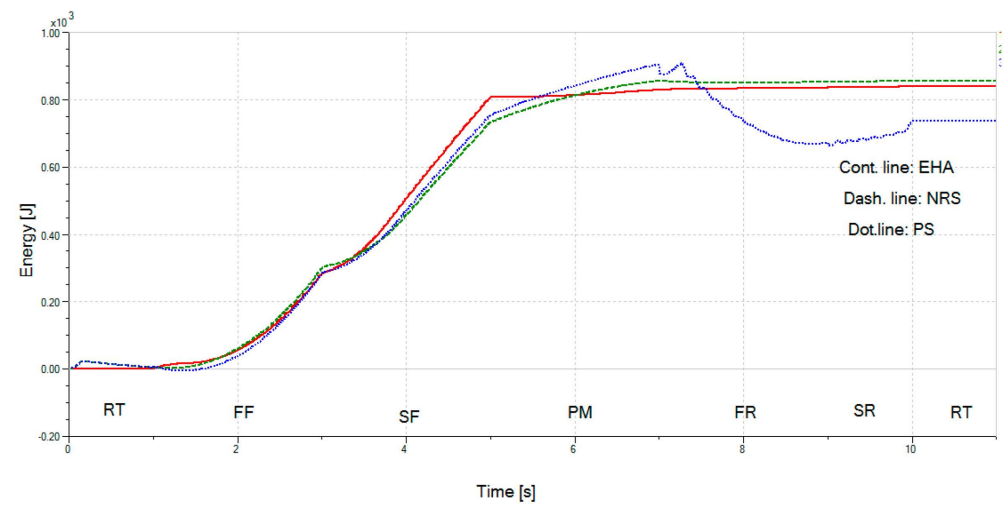

(b)

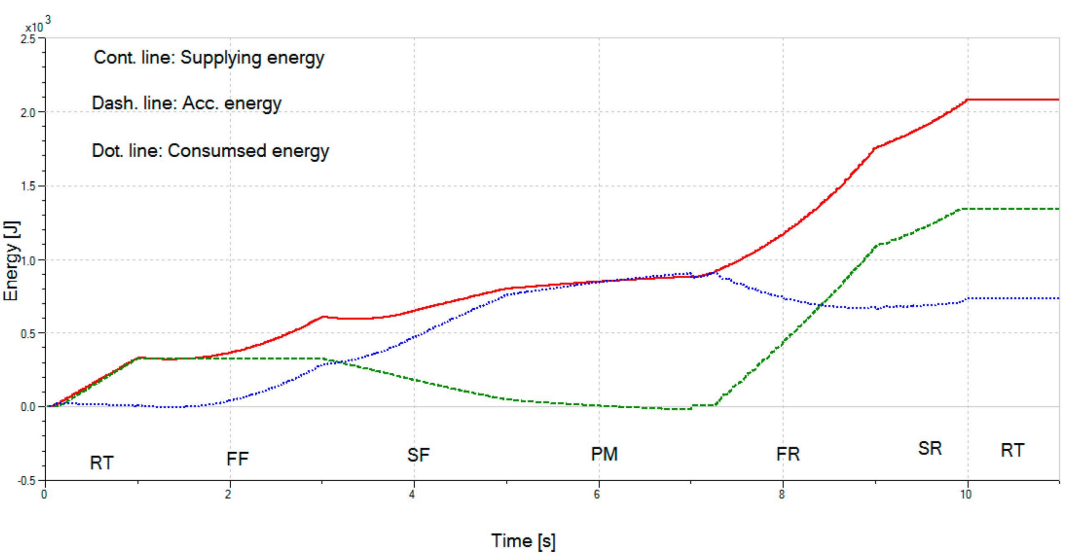

(c)

Figure 14. Cont. 


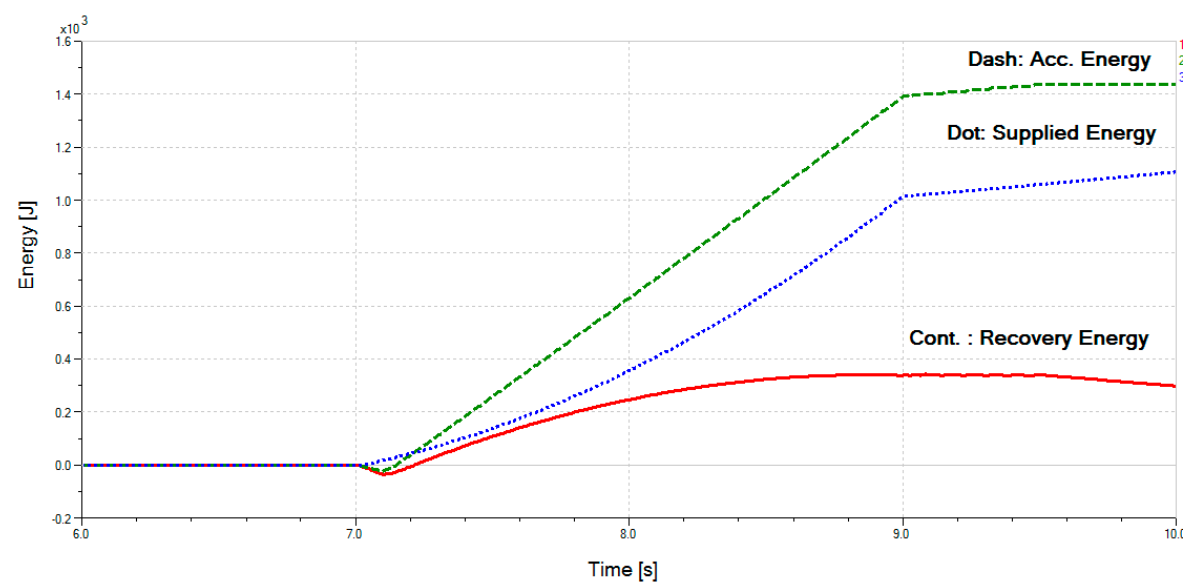

(d)

Figure 14. (a) Cylinder position response; (b) consumption energy of the system for the PS, NRS and EHA strategies; (c) energy flow of the system for PS strategy; (d) energy of the system in FR and SR phases of the cycle.

\subsection{Effect of the Accumulator Parameters on Energy Recovery Potential of the System}

The system reveals that it is able to recover energy of opposite external force for the PS strategy. The recovery energy is stored in the accumulator during returning phases of a pressing cycle. The maximum theoretical recoverable energy from the spring is defined in Equation (6).

$$
E_{\text {reco_max }}=E_{p, s p}-E_{p, s l}=\frac{1}{2} K x^{2}-m g h
$$

In Equation (6), $E_{p, s p}$ is the potential energy of the spring and $E_{p, s l}$ is the potential energy of the slider, $K$ is the stiffness of the spring, $x$ is the displacement of the slider, $m$ is mass of the slider, $g$ is the gravity of acceleration, and the height of the slider is $h$.

During the recovering phase, the energy of the accumulator consists of recovery energy of the load and the supplying energy from the pump. Therefore, the supplying energy should be estimated in order to calculate the value of recovery energy, via the energy recovery factor $(R F)$, as expressed in Equation (7):

$$
R F=\frac{E_{\text {recover }}}{E_{\text {reco-max }}}=\frac{\left(E_{\text {fin }-a c}-E_{\text {int-ac }}-E_{m}-E_{p, s p}\right) \mu_{m}}{E_{\text {reco-max }}}
$$

In Equation (7), $E_{f i n-a c}$ and $E_{i n t-a c}$ are the hydraulic energy of the accumulator at the final and beginning states, respectively. Electric motor efficiency $\mu_{m}$ is selected as 1 in this study. $E_{\text {recover }}$ is the hydraulic energy that is recovered and stored in the accumulator. $E_{\text {fin-ac }}$ and $E_{\text {int-ac }}$ are estimated by using Equation (1) with different conditions.

For partial recovery applications, the energy recovery factor of the system versus pre-charge pressure and volume of the accumulator is described in Figure 15, in which the setting value of the relief valve in the hydraulic circuit is 200 bar and that value is not increased because it depends on type of the pump. It is revealed that the RF varies, and it reaches the high value about 0.6 when pre-charge pressure of the accumulator is 60 bar. These values are reduced when the pre-charge pressure is too high or that is too low. When it is set too low, the slider goes very fast. When the pre-charge pressure is increased, the operating pressure of the system is increased and reaches the setting pressure of the relief valve. Moreover, when the volume of the accumulator increases, the recovery factor is also increased and vice versa. It is observed that the effect of the pre-charge pressure to the energy recovery factor is higher than the effect of the volume. 


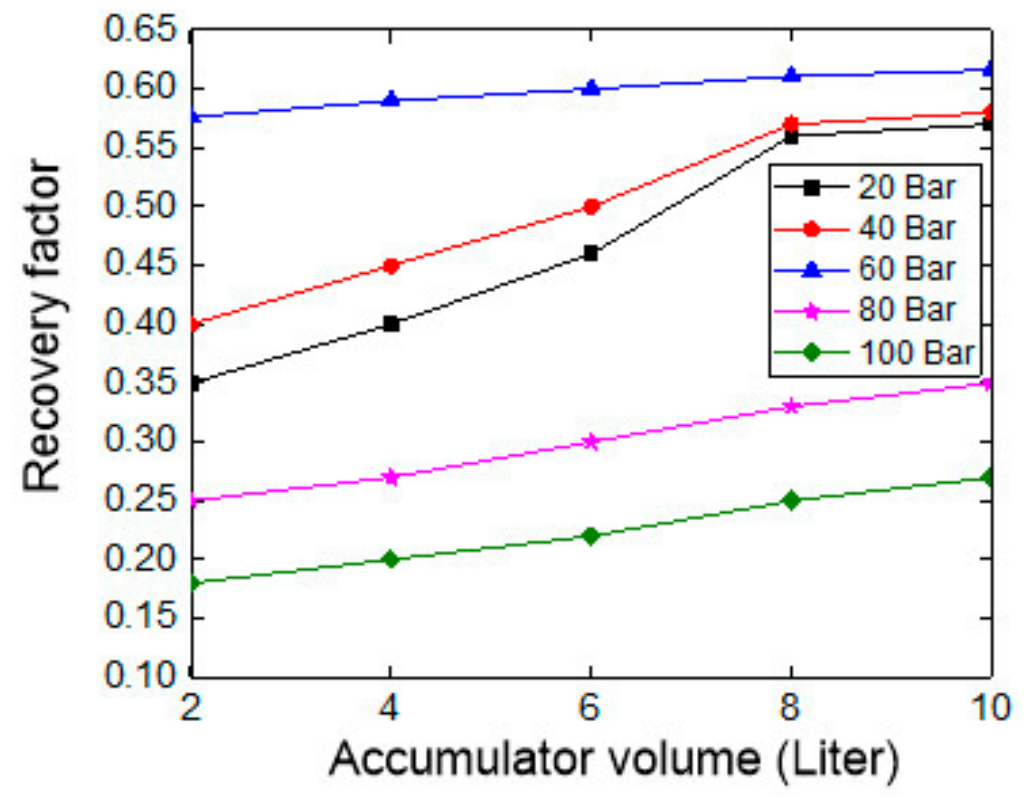

Figure 15. Energy recovery factor versus accumulator volume under the various pressure of the accumulator.

\section{Experimental Results}

For the purpose of verifying the analysis results from the model, a prototype of the developed hydraulic system is set up as shown in Figure 16 and the structure of the experimental model is described in Figure 17. In which the position of the hydraulic cylinder is measured by a wire sensor meanwhile the two pressure sensors type KH-15 manufactured by Nagano Keiki are employed to measure the pressure at the outlet of the pump and inlet of the accumulator. The speed sensor and torque transducer are SETech products. All of the data from the sensors are transmitted to the personal computer (PC) through NI card 6221 worked as an A/D converter. In addition, the fixed displacement bidirectional van pump is driven by the AC servo motor. The signal from the PC can be sent to the motor driver through the converter for aiming the adjustment of the motor's speed according to wanted working condition.

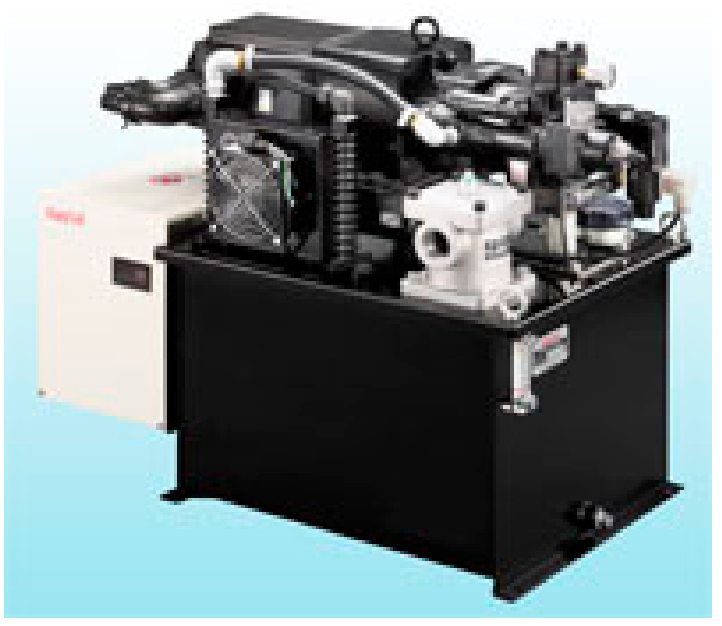

Figure 16. First stage model. 


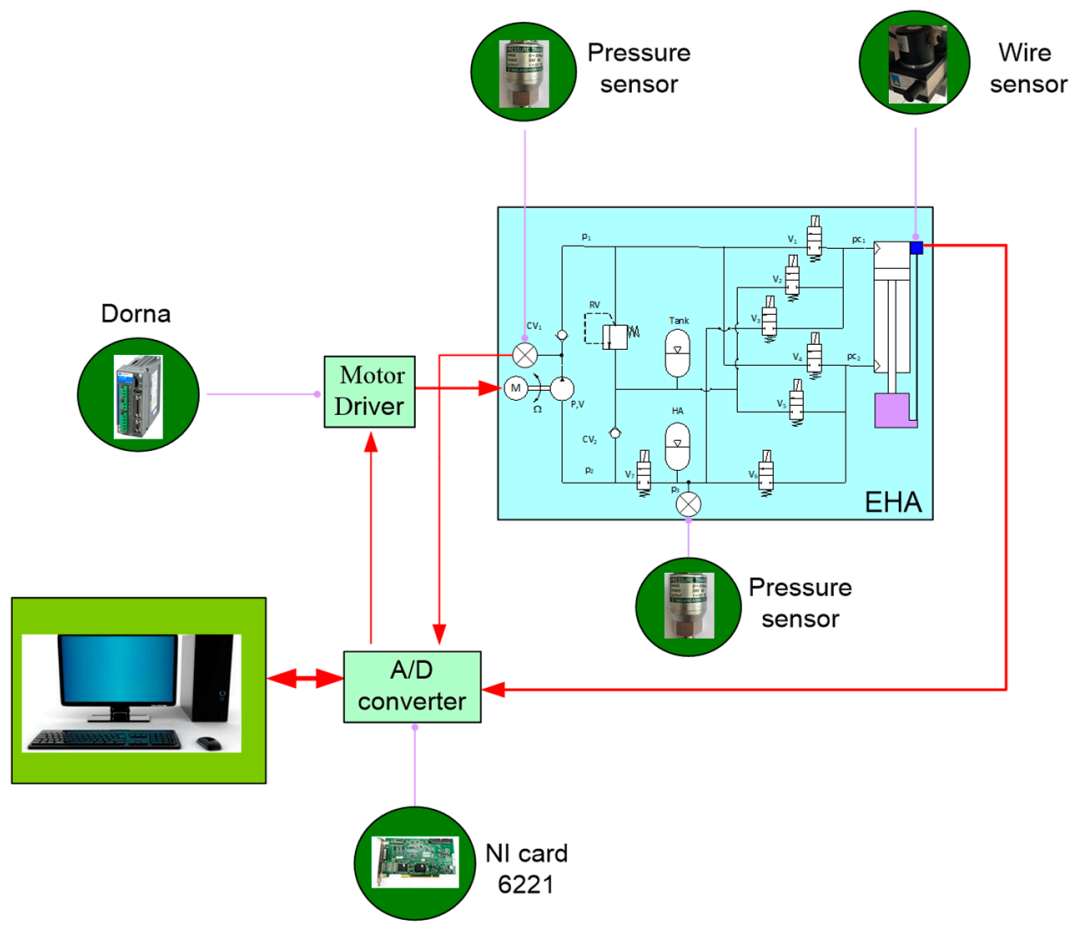

Figure 17. Block diagram of experimental model.

In the same manner of the operation of the simulation model, the real position response of the slider is compared with that measured from the simulation model as shown in Figure 18a. It is noteworthy that the experimental result is in good in agreement with the position error of approximately $1.5 \mathrm{~mm}$ in PM phase. Although the pressure response obtained from the experimental appears as the oscillation, it almost tracks well the reference. This oscillating phenomenon is affected by the elasticity of the line system, which indicates that the oscillation of the pressure curve can be reduced according to the increase in the compressibility of the line system. Indeed, installing the accumulator on the return line leads to the elasticity of this line increased. The result is the oscillation of the pressure $\mathrm{P}_{3}$ (plotted by the dashed line in Figure 18c) reduced compared with that of the pressure at the outlet of the pump (denoted by the dashed line in Figure 18b).

The speed and torque of the pump for PS control strategy by simulation and experiment are shown in Figure 19. It is observed that, both the simulated and measured speed are affected when the system changes its phases. At the beginning of SF phase, torque of the motor is negative because pressure of the inlet port is higher that of the outlet port of the pump. That phenomenal is a result of the phase change of the system from RNOM mode to RUNO mode. The value of motor torque is increased during FR phase and reached the highest value in SR phase due to pressure in the accumulator for recovery modes.

It is observed that, at the end of first cycle, the pressure of the accumulator of the ending is higher than that of the beginning as shown in Figure 18c because recovery energy in returning phases is stored in the accumulator. The speed of the pump at the beginning and the ending is different, as shown in Figure 19a, because the system charges the accumulator in a second for first cycle. Therefore, only position of the cylinder is repetitive cycle instead of any system parameter such as pressure of the accumulator or speed of the pump. For overcoming this phenomenon, a charging accumulator strategy or a power management for the total cycle should be added in next study. 


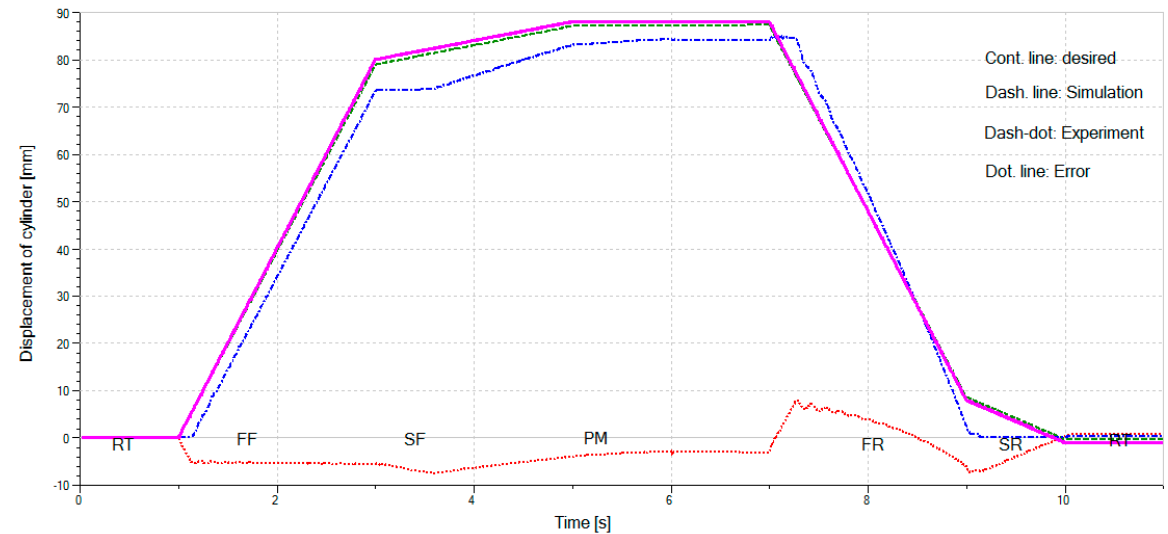

(a)

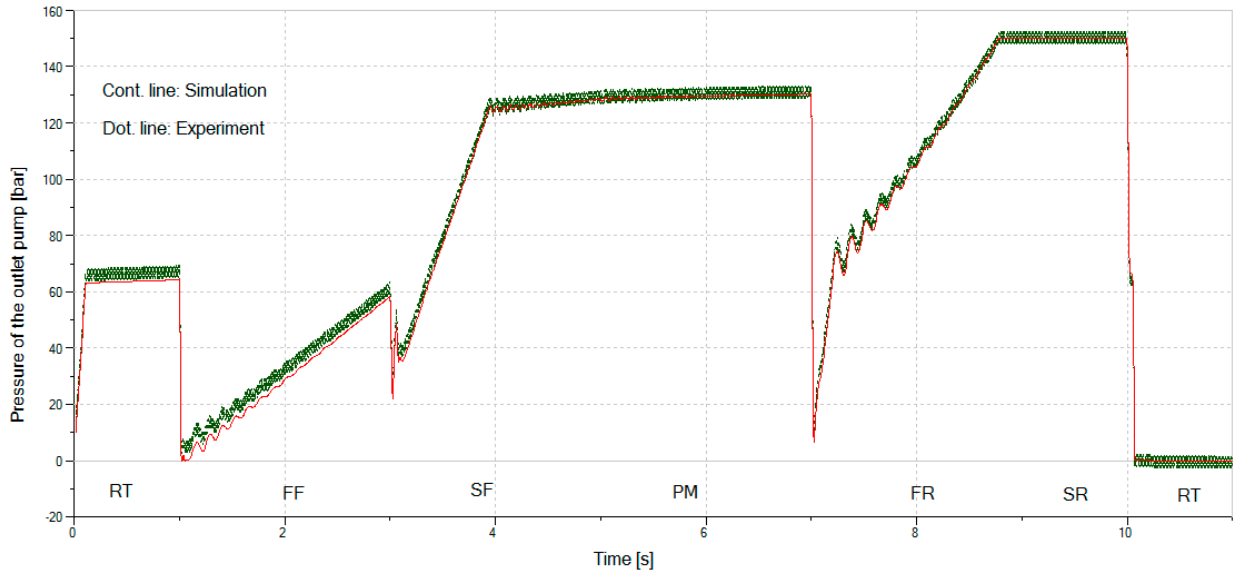

(b)

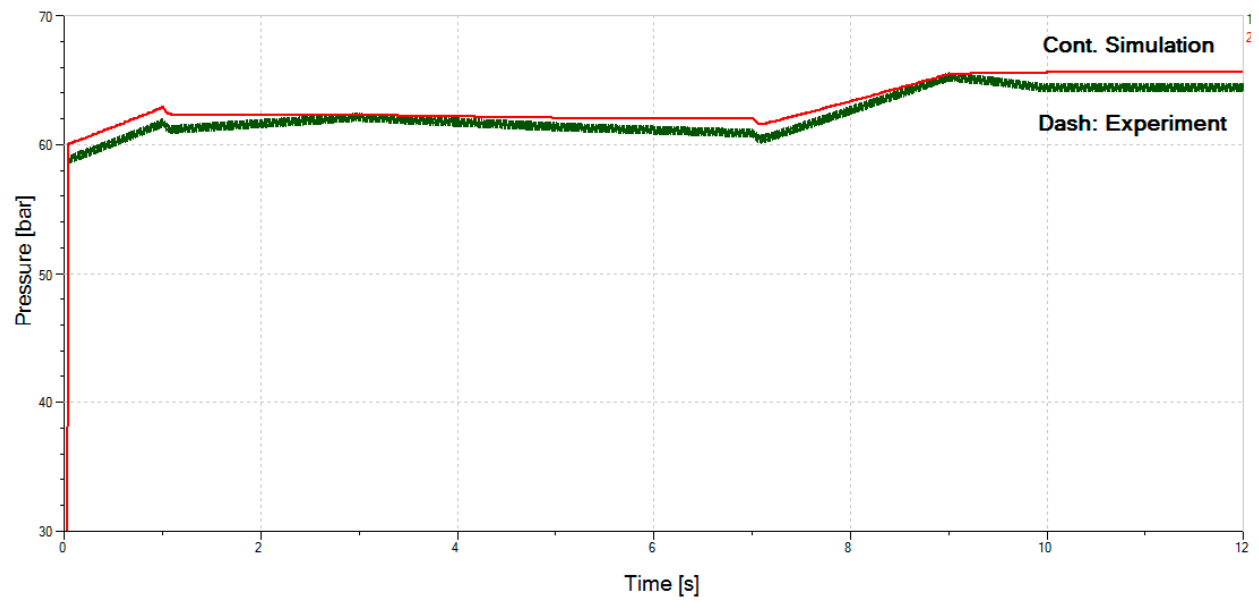

(c)

Figure 18. (a) The time history of the position; (b) pressure at outlet of the pump; (c) pressure in the inlet of the accumulator. 


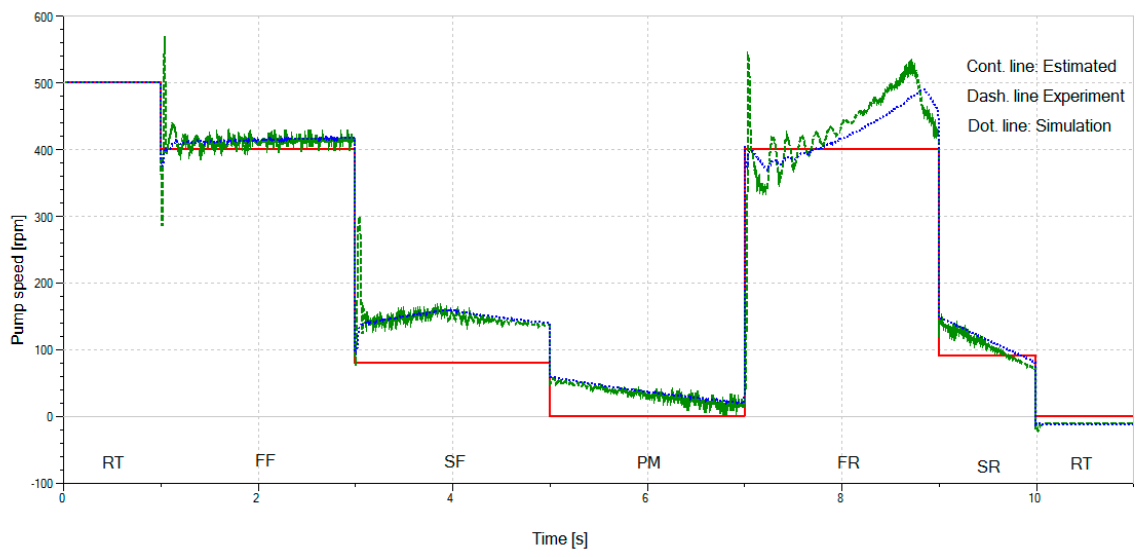

(a)

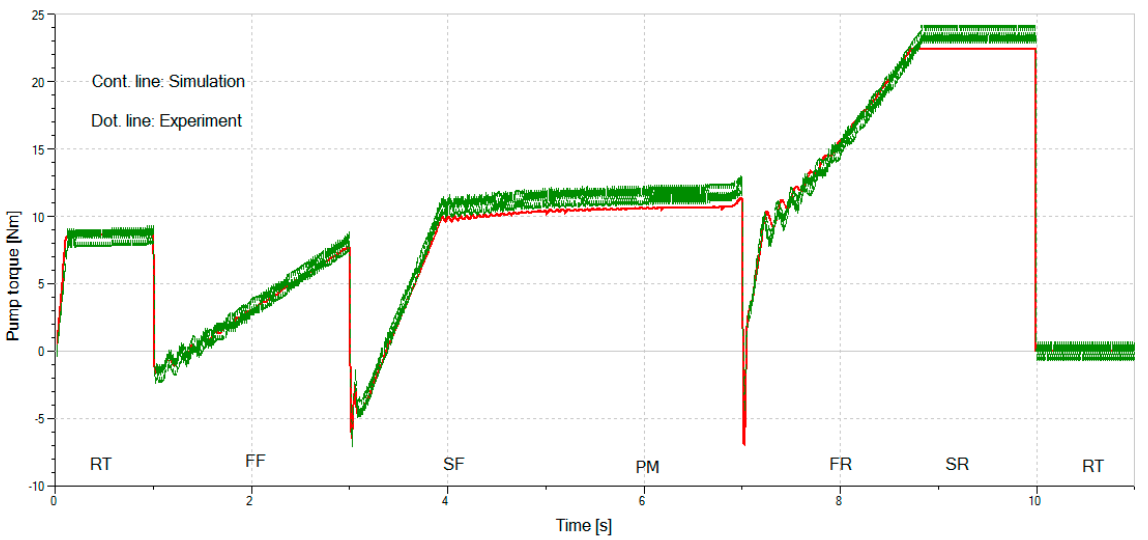

(b)

Figure 19. (a) Speed of the pump. (b) Torque of the pump.

The energy of the system in simulation and experiment for the pressing cycle is described in Figure 20a. The supplying energy is calculated by indirectly measured torque and speed of the motor. It is observed that, there are errors in simulation and measured values for supplying, recovery and consumed energy, in which the value of measured supplying energy is higher than that of the simulation one. While the value of measured recovery energy is lower than that of the simulation one. As a result, the measured consumed energy is higher than that of the simulation one. It is observed that, the system consumes about $770 \mathrm{~J}$ while that value in simulation is about $700 \mathrm{~J}$ to finish this cycle.

For this system, only the PS strategy is able to recover energy by using the accumulator. The supplying energy and accumulator energy of the system during returning phases are described in Figure 20b. From the figure, the energy of the accumulator in simulation (plotted by the dot. line) is higher than that of experiment (plotted by the dashed-dot. line). While the supplied energy of the system in simulation (plotted by the dashed line) is lower than that of experiment. The simulation supplied energy is $1100 \mathrm{~J}$ but that value in measured is $1160 \mathrm{~J}$. Therefore, error between the experiment and the simulation result is about $5 \%$. While values of accumulator energy for simulation and measured are $1435 \mathrm{~J}$ and $1364 \mathrm{~J}$, respectively. As a result, value RF of the system in experiment is about $50 \%$, which implies that measured RF value is lower than that of simulation about $8 \%$. 


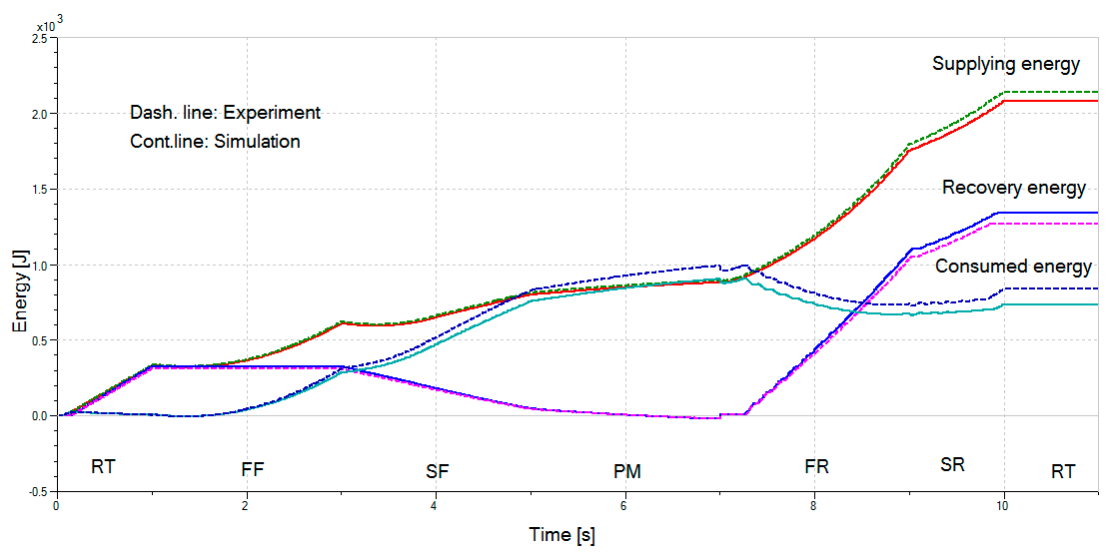

(a)

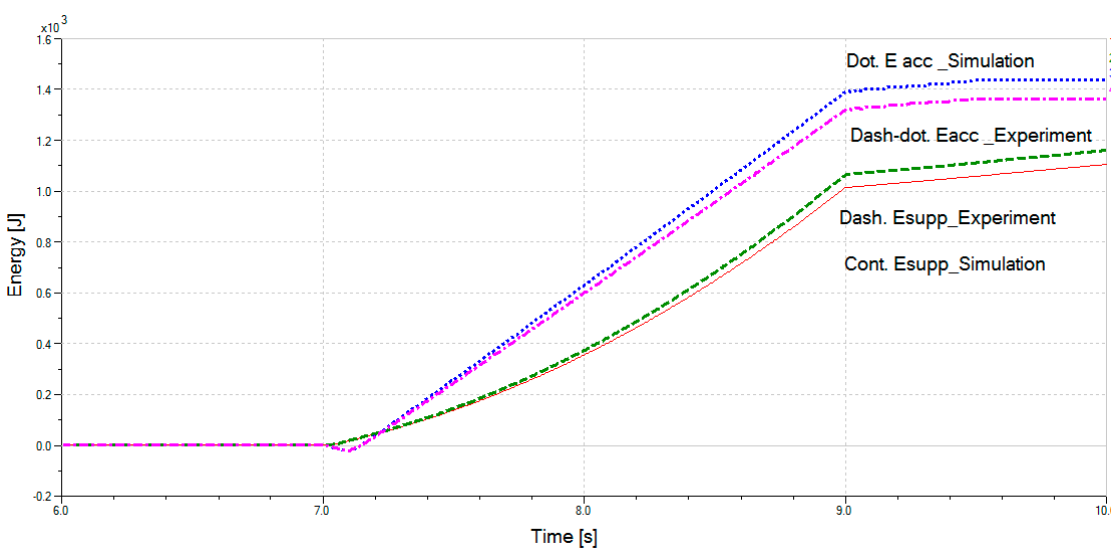

(b)

Figure 20. (a) Energy of the system; (b) the energy recovery of the system.

\section{Conclusions}

A novel reconfiguration energy saving hydraulic system is proposed and investigated in this paper. Control strategies are suggested for the system and are brought into analysis. Advantages of the system are energy recovery and high velocity or force factor. In a given profile, the proposed system is saving about $20 \%$ consumed energy when compared with a typical without energy recovery EHA system. That saving energy ability is due to external load is recoverable. In this study, about $50 \%$ of energy from the opposite load is recovered and this value depends on relationship pre-charge pressure of the accumulator and value of the load.

Besides, the velocity of the cylinder is twice higher than that value of a typical EHA system with the same size of hydraulic equipment, while the torque at the shaft of the pump is lower than that of an EHA system to yield the same output force of hydraulic cylinder. Which implies that the size of hydraulic pump and power of electric motor are reduced over that in a EHA system.

Through experimental verifying, high nonlinearities of a hydraulic system are well designed by using AMESim model. Although the system still has some notches when the valves shift, this value is kept low and acceptable in applications such as industrial presses where energy saving is the dominant consideration. Furthermore, the closed loop controller for the tracking position should be added to improve the dynamic response as well the accuracy of the system.

Author Contributions: Conceptualization, T.H.H.; methodology, T.D.L. and T.H.H.; software, T.H.H.; validation, T.H.H.; formal analysis, T.H.H.; investigation, T.D.L.; resources, T.H.H.; data curation, T.D.L.; writing—original draft preparation, T.D.L. and T.H.H.; writing—review and editing, T.D.L.; 
visualization, T.D.L. and T.H.H.; supervision, T.D.L. and T.H.H. All authors have read and agreed to the published version of the manuscript.

Funding: This research is funded by Vietnam National University Ho Chi Minh City (VNU-HCM) under grant number C2018-20-03. We acknowledge the support of time and facilities from Ho Chi Minh City University of Technology (HCMUT), VNU-HCM for this study.

Institutional Review Board Statement: No applicable.

Informed Consent Statement: No applicable.

Data Availability Statement: No applicable.

Conflicts of Interest: The authors declare no conflict of interest.

\section{References}

1. Manring, N.D.; Fales, R.C. Hydraulic Control System, 2nd ed.; Wiley: Hoboken, NJ, USA, 2020.

2. Zhao, K.; Liu, Z.; Yu, S.; Li, X.; Huang, H.; Li, B. Analytical energy dissipation in large and medium-sized hydraulic press. J. Clean. Prod. 2015, 103, 908-915. [CrossRef]

3. Gao, M.; He, K.; Li, L.; Wang, Q. A Review on Energy Consumption, Energy Efficiency and Energy Saving of Metal Forming Processes from Different Hierarchies. Processes 2019, 7, 357. [CrossRef]

4. Liu, Z.; Wang, Y.; Huang, H.; Li, X.; Li, L.; Zhou, D. An Energy Matching Method for Hydraulic Press Group Based on Operation Load Profile. Procedia CIRP 2016, 48, 219-223. [CrossRef]

5. Li, L.; Huang, H.; Zhao, F.; Sutherland, J.W.; Liu, Z. An Energy-Saving Method by Balancing the Load of Operations for Hydraulic Press. IEEE/ASME Trans. Mechatron. 2017, 22, 2673-2683. [CrossRef]

6. Liu, Z.; Huang, H.; Zhao, F.; Li, L.; Liu, Z. An Improved Energy-Saving Design Method for Drive System with Multi Motor-Pumps by Using Genetic Algorithm. Procedia CIRP 2019, 80, 79-83.

7. Song, W.; Liu, S.; Pan, H.; Zhu, S. Investigation on the design of hydraulic high-speed punching press with a large press force and a long press stroke. Adv. Mech. Eng. 2016, 8, 1-12. [CrossRef]

8. Yao, J.; Lu, B.; Zhang, C.; Sadatomi, M. Optimal Design of Hydraulic System for an Industrial Press Machine for Performance Improvement and Noise Reduction. Open J. Mech. Eng. 2013, 1, 1-16.

9. Vacca, A.; Franzoni, G. Hydraulic Fluid Power; Wiley: Hoboken, NJ, USA, 2021; pp. 379-413.

10. Ligang, H.; Yu, T.; Jio, Z.; Li, Y. Active Load-Sensitive Electro-Hydrostatic Actuator for More Electric Aircraft. Appl. Sci. 2020, 10, 6978.

11. Casoli, P.; Scolari, P.; Minav, T.; Rundo, M. Comparative Energy Analysis of a Load Sensing System and a Zonal Hydraulics for a 9-Tonne Excavator. Actuators 2020, 9, 39. [CrossRef]

12. Lovrec, D.; Kastrevc, M.; Ulaga, M. Ectro hydraulic load sensing with a speed controlled hydraulic supply system on forming machines. Int. J. Adv. Manuf. Technol. 2008, 41, 1066-1075. [CrossRef]

13. Huova, M.; Aalto, A.; Linjama, M.; Huhtala, K. Study of Energy Losses in Digital Hydraulic Multi-Pressure Actuator. In Proceedings of the 15th Scandinavian International Conference on Fluid Power, SICFP'17, Linköping, Sweden, 7-9 June 2017; pp. 214-223.

14. Heybroek, K.; Sahlman, M. A hydraulic hybrid excavator based on multi-chamber cylinders and secondary control—Design and experimental validation. Int. J. Fluid Power 2018, 19, 91-105. [CrossRef]

15. Kalaiarassan, G.; Krishnamurthy, K. Digital hydraulic single-link trajectory tracking control through flow-based control. Meas. Control 2019, 52, 775-787. [CrossRef]

16. Sell, P.N.; Johnston, D.N.; Plummer, A.R.; Kudzma, S. Control of a fast switching valve for digital hydraulics. In Proceedings of the 13th Scandinavian International Conference on Fluid Power, SICFP2013, Linköping, Sweden, 3-5 June 2013; pp. $497-503$.

17. Pourmovahed, A.; Beachey, N.; Fronczak, F. Modeling of a Hydraulic Energy Regeneration System-Part I: Analytical Treatment. ASME 1992, 114, 155-159.

18. Kim, C.S.; Lee, C.O. Speed control of an overcenetered variable displacement hydraulic motor with a load torque observer. Control. Eng. Pract. 1996, 4, 1563-1570. [CrossRef]

19. Guo, M.; Wang, L.; Jia, Z.; Liang, J. Wang Application of Hydraulic Transformer on Energy Saving for Boom System of Hybrid Hydraulic Excavator. Appl. Mech. Mater. 2017, 868, 118-123.

20. Lee, S.; Li, Y.P. A Hardware-In-The-Loop (HIL) Testbed for Hydraulic Transformers Research. In Proceedings of the SICFP2017, Linköping, Sweden, 7-9 June 2017; pp. 179-185.

21. Alle, N.; Hiremath, S.S.; Makaram, S.; Subramaniam, K.; Talukdar, A. Review on electro hydrostatic actuator for flight control. Intern. J. Fluid Power 2016, 17, 125-145.

22. Du, C.; Plummer, A.R.; Johnston, D.N. Performance analysis of an energy-efficient variable supply pressure electro-hydraulic motion control system. Control. Eng. Pract. 2016, 48, 10-21. [CrossRef]

23. Hagen, D.; Padovani, D.; Choux, M. A Comparison Study of a Novel Self-Contained Electro-Hydraulic Cylinder versus a Conventional Valve-Controlled Actuator-Part 1: Motion Control. Actuators 2019, 8, 79. [CrossRef] 
24. Sharghi, A.H.; Mohammadi, R.K.; Farrokh, M.; Zolfagharysaravi, S. Feed-Forward Controlling of Servo-Hydraulic Actuators Utilizing a Least-Squares Support-Vector Machine. Actuators 2020, 9, 11. [CrossRef]

25. Wang, L.; Book, W.J.; Huggins, J.D. Application of Singular Perturbation Theory to Hydraulic Pump Controlled Systems. IEEE/ASME Trans. Mechatron. 2012, 17, 251-259. [CrossRef]

26. Lin, Y.; Shi, Y.; Burton, R. Modeling and Robust Discrete-Time Sliding-Mode Control Design for a Fluid Power Electrohydraulic Actuator (EHA) System. IEEE/ASME Trans. Mechatron. 2013, 18, 1-10. [CrossRef]

27. Guzzella, L.; Sciarretta, A. Vehicle Propulsion Systems: Introduction to Modeling and Optimization; Springer: Berlin/Heidelberg, Germany, 2007.

28. Jaiswal, S.; Sopanen, J.; Mikkola, A. Efficiency comparison of various friction models of a hydraulic cylinder in the framework of multibody system dynamics. Nonlinear Dyn. 2021, 104, 3497-3515. [CrossRef]

29. Tran, X.B.; Yanada, H. Dynamic Friction Behaviors of Pneumatic Cylinders. Intell. Control Autom. 2013, 4, 180-190. [CrossRef]

30. Dulger, C.L.; Kirecci, A. Motion Control and Implementation for an AC Servomotor System. Model. Simul. Eng. 2007, 2007, 50586. [CrossRef]

31. Wu, Y.; Wang, Z.; Li, Y.; Chen, W.; Du, R.; Chen, Q. Characteristic Modeling and Control of Servo Systems with Backlash and Friction. Math. Probl. Eng. 2014, 2014, 328450. [CrossRef]

32. Sheng, H.W.; Wei, L.C.; Lo, H.P.; Shiuh, Y.S. Precision Control and Compensation of Servomotors and Machine Tools via the Disturbance Observer. IEEE Trans. Ind. Electron. 2009, 57, 420-431. 